Supporting Information

\title{
Selective Hydrogenation of Amides to Amines and Alcohols Catalyzed by Improved Iron Pincer Complexes
}

Felix Schneck, ${ }^{\dagger}$ Maik Assmann, ${ }^{\dagger}$ Markus Balmer, ${ }^{\dagger}$ Klaus Harms $^{\dagger}$ and Robert Langer ${ }^{\dagger, \star, *}$

1. Details for single crystal $X$-Ray diffraction analysis

2. Spectroscopic data

3. NMR spectra

apepartment of Chemistry, Philipps-Universität Marburg, Hans-Meerwein-Str., 35043 Marburg, Germany, Fax: (+)49-6421-2825653, E-mail: robert.langer@chemie.uni-marburg.de

${ }^{b}$ Lehn Institute of Functional Materials (LIFM), Sun Yat-Sen University (SYSU), Xingang Road West, Guangzhou 510275, PR China. 


\section{Details for single crystal $X$-Ray diffraction analysis}

Table S1 Crystallographic data for 1a, $1 \mathrm{~d}$ and $\mathbf{3 c}$.

\begin{tabular}{|c|c|c|c|}
\hline Compound & 1a & 1d & $3 \mathbf{c}$ \\
\hline Empirical formula & $\mathrm{C}_{13} \mathrm{H}_{29} \mathrm{Br}_{2} \mathrm{FeNOP}_{2}$ & $\mathrm{C}_{29} \mathrm{H}_{29} \mathrm{Br}_{2} \mathrm{FeNOP}_{2}$ & $\mathrm{C}_{28} \mathrm{H}_{59} \mathrm{~B}_{2} \mathrm{NP}_{2}$ \\
\hline Formula weight $/ \mathrm{g} \cdot \mathrm{mol}^{-1}$ & 492.98 & 685.14 & 493.32 \\
\hline$T / \mathrm{K}$ & $100(2)$ & $100(2)$ & $100(2)$ \\
\hline Crystal system & Monoclinic & Orthorhombic & Triclinic \\
\hline Space group & $P 2_{1} / c$ & $P b c a$ & $P \overline{1}$ \\
\hline$a / \AA$ & $7.8160(16)$ & $16.489(3)$ & $6.4856(8)$ \\
\hline$b / \AA$ & $13.282(3)$ & $17.020(3)$ & $15.051(4)$ \\
\hline$c / \AA$ & $18.765(4)$ & $19.647(4)$ & $17.126(4)$ \\
\hline$\alpha /^{\circ}$ & 90.00 & 90.00 & $68.713(18)$ \\
\hline$\beta /^{\circ}$ & $100.14(3)$ & 90.00 & $89.288(16)$ \\
\hline$\gamma /{ }^{\circ}$ & 90.00 & 90.00 & $78.376(15)$ \\
\hline$V / \AA^{3}$ & $1917.6(7)$ & $5513.8(18)$ & $1522.4(6)$ \\
\hline$Z$ & 4 & 8 & 2 \\
\hline$\rho_{\text {cald }} / \mathrm{g} \cdot \mathrm{cm}^{-3}$ & 1.708 & 1.651 & 1.076 \\
\hline$\mu\left(\mathrm{MoK}_{\alpha}\right) / \mathrm{mm}^{-1}$ & 5.117 & 3.586 & 0.159 \\
\hline $\mathrm{F}(000)$ & 992 & 2752 & 548 \\
\hline $2 \theta$ range $^{\circ}$ & $3.78-53.10$ & $4.786-56.638$ & $2.558-50.498$ \\
\hline Reflections measured & 14373 & 63936 & 7362 \\
\hline Independent reflections & $3870\left(R_{\text {Int }}=0.0721\right)$ & $6844\left(R_{\mathrm{Int}}=0.0880\right)$ & 7362 \\
\hline Ind. reflections $(I>2 \sigma(I))$ & 3665 & 4806 & 3016 \\
\hline Parameters/Restraints & $189 / 0$ & $303 / 0$ & $327 / 0$ \\
\hline$R_{1}(I>2 \sigma(I))$ & 0.0247 & 0.0488 & 0.0416 \\
\hline$w R_{2}($ all data $)$ & 0.0604 & 0.0964 & 0.0773 \\
\hline GooF (all data) & 1.110 & 1.056 & 0.588 \\
\hline Max. peak/hole/e $\cdot \AA^{-3}$ & $0.846 /-0.637$ & $0.707 /-0.956$ & $0.251 /-0.300$ \\
\hline $\mathrm{CCDC}$ & 1449037 & 1449038 & 1449041 \\
\hline
\end{tabular}


Table S2 Crystallographic data for 7c, 8c and 10e.

\begin{tabular}{|c|c|c|c|}
\hline Compound & $7 c \cdot 1^{1 / 2} \mathrm{C}_{6} \mathrm{H}_{14}$ & $8 c$ & $10 \mathrm{e}$ \\
\hline Empirical formula & $\mathrm{C}_{57} \mathrm{H}_{113} \mathrm{~B}_{3} \mathrm{FeN}_{2} \mathrm{OP}_{4} \cdot \mathrm{C}_{9} \mathrm{H}_{21}$ & $\mathrm{C}_{56} \mathrm{H}_{120} \mathrm{~B}_{6} \mathrm{~N}_{2} \mathrm{P}_{4}$ & $\mathrm{C}_{22} \mathrm{H}_{45} \mathrm{FeNO}_{2} \mathrm{P}_{2}$ \\
\hline Formula weight $/ \mathrm{g} \cdot \mathrm{mol}^{-1}$ & 1183.91 & 1010.28 & 473.38 \\
\hline$T / \mathrm{K}$ & $100(2)$ & $100(2)$ & $100(2)$ \\
\hline Crystal system & Triclinic & Monoclinic & Orthorhombic \\
\hline Space group & $P \overline{1}$ & $C 2 / c$ & $P 2_{1} 2_{1} 2_{1}$ \\
\hline$a / \AA$ & $14.370(3)$ & $31.6990(19)$ & $11.892(5)$ \\
\hline$b / \AA$ & $14.854(3)$ & $11.9893(7)$ & $14.039(5)$ \\
\hline$c / \AA$ & $16.803(3)$ & $17.2979(10)$ & $15.030(5)$ \\
\hline$\alpha /^{\circ}$ & $93.23(3)$ & 90.00 & 90.00 \\
\hline$\beta /{ }^{\circ}$ & $93.46(3)$ & $105.538(3)$ & 90.00 \\
\hline$\gamma /{ }^{\circ}$ & $98.10(3)$ & 90.00 & 90.00 \\
\hline$V / \AA^{3}$ & $3536.7(12)$ & $6333.8(7)$ & 2509.3(16) \\
\hline$Z$ & 2 & 4 & 4 \\
\hline$\rho_{\text {cald }} / \mathrm{g} \cdot \mathrm{cm}^{-3}$ & 1.112 & 1.064 & 1.253 \\
\hline$\mu\left(\mathrm{MoK}_{\alpha}\right) / \mathrm{mm}^{-1}$ & 0.343 & 0.155 & 0.745 \\
\hline $\mathrm{F}(000)$ & 1306 & 2256 & 1024 \\
\hline $2 \theta$ range ${ }^{\circ}$ & $2.44-51.02$ & $4.588-50.632$ & $4.368-54.278$ \\
\hline Reflections measured & 33399 & 78682 & 11617 \\
\hline Independent reflections & $12325\left(R_{\mathrm{Int}}=0.0743\right)$ & $5768\left(R_{\mathrm{Int}}=0.0337\right)$ & $5542\left(R_{\mathrm{Int}}=0.0235\right)$ \\
\hline Ind. reflections $(I>2 \sigma(I))$ & 9942 & 4864 & 5183 \\
\hline Parameters/Restraints & $729 / 0$ & $319 / 0$ & $269 / 0$ \\
\hline$R_{1}(I>2 \sigma(I))$ & 0.0731 & 0.0696 & 0.0292 \\
\hline$w R_{2}($ all data) & 0.2657 & 0.1955 & 0.0592 \\
\hline GooF (all data) & 1.049 & 1.043 & 1.020 \\
\hline Max. peak/hole/e $\cdot \AA^{-3}$ & $1.751 /-0.529$ & $1.381 /-0.756$ & $0.540 /-0.177$ \\
\hline $\mathrm{CCDC}$ & 1449039 & 1449042 & 1449040 \\
\hline
\end{tabular}


Table S3. Selected bond lengths $(\AA)$ and angles $\left({ }^{\circ}\right)$ for complexes 1a-d.

\begin{tabular}{rccccccc}
\hline Complex & $\mathrm{R}=$ & $\mathrm{Fe}-\mathrm{N}$ & $\mathrm{Fe}-\mathrm{C}$ & $\mathrm{Fe}-\mathrm{P}$ & $\mathrm{Fe}-\mathrm{Br}$ & $\mathrm{C}-\mathrm{O}$ & $\mathrm{P}-\mathrm{Fe}-\mathrm{P}$ \\
\hline $\mathbf{1 a}$ & Et & $2.067(2)$ & $1.755(2)$ & $2.265(1)-2.267(1)$ & $2.458(1)-2.473(1)$ & $1.130(3)$ & $167.39(2)$ \\
$\mathbf{1 \mathbf { b } ^ { [ a ] }}$ & ${ }^{\mathrm{Pr}}$ & $2.067(1)-$ & $1.751(3)-$ & $2.291(1)-2.305(1)$ & $2.470(1)-2.490(1)$ & $1.140(3)-$ & $167.22(3)-$ \\
& & $2.071(2)$ & $1.758(3)$ & & & $1.149(3)$ & $168.32(3)$ \\
cis-1d & $\mathrm{Ph}$ & $2.040(3)$ & $1.735(1)$ & $2.239(1)-2.260(1)$ & $2.456(1)-2.509(1)$ & 1.136 & $170.29(4)$ \\
trans-1d & $\mathrm{Ph}$ & $2.040(3)$ & $1.733(1)$ & $2.239(1)-2.260(1)$ & $2.462(1)-2.509(1)$ & 1.127 & $170.29(4)$ \\
\hline
\end{tabular}

${ }^{[a]}$ Bond lengths and angles have been taken from ref. ${ }^{1}$ (CCDC 949531).

\section{Spectroscopic data}

Selected NMR spectroscopic data is summarized in Table S4-S6.

Table S4. Spectroscopic data for $\left[\left(\mathrm{R}-\mathrm{PN}{ }^{H} \mathrm{P}\right) \mathrm{Fe} \mathrm{X}_{2}(\mathrm{CO})\right](\mathbf{1 a}-\mathbf{d})$

\begin{tabular}{ccccc}
\hline Complex & $\mathrm{R}=$ & $\mathrm{X}=$ & $\tilde{v}_{C O} / \mathrm{cm}^{-1}$ & $\delta_{\mathrm{p}}(\mathrm{Fe}-P) / \mathrm{ppm}$ \\
\hline $\mathbf{1 a}$ & $\mathrm{Et}$ & $\mathrm{Br}$ & 1936 & $64.4^{*}$ \\
$\mathbf{1 b}^{[\mathrm{b}]}$ & ${ }^{i} \mathrm{Pr}$ & $\mathrm{Br}$ & 1941 & 68.4 \\
$\mathbf{1 c}^{[\mathrm{c}]}$ & $\mathrm{Cy}$ & $\mathrm{Cl}$ & 1944 & 58.9 \\
cis-1d $_{\text {rans }}-\mathbf{1 d}$ & $\mathrm{Ph}$ & $\mathrm{Br}$ & 1916 & 42.4 \\
td & $\mathrm{Ph}$ & $\mathrm{Br}$ & 1940 & 70.4
\end{tabular}

${ }^{[a]}$ The ${ }^{31} \mathrm{P}\left\{{ }^{1} \mathrm{H}\right\}$ NMR spectra were acquired in $\mathrm{CD}_{2} \mathrm{Cl}_{2}$ except for 1a which was acquired in $\mathrm{CDCl}_{3}{ }^{[\mathrm{b}]}$ Spectroscopic data has been taken from ref. ${ }^{1,}{ }^{[c]}$ Spectroscopic data has been taken from ref. ${ }^{2}$.

Table S5. Selected NMR spectroscopic data for R-PN ${ }^{H} \mathrm{P}\left\{\mathrm{BH}_{3}\right\}_{2}(\mathbf{3 c}-\mathbf{e})$ and $\mathbf{8 c}$.

\begin{tabular}{cccc}
\hline Compound & $\mathrm{R}=$ & $\delta_{\mathrm{P}} / \mathrm{ppm}$ & $\delta_{\mathrm{B}} / \mathrm{ppm}$ \\
\hline $\mathbf{3 c}$ & $\mathrm{Cy}$ & 24.2 & -42.7 \\
$\mathbf{8 c}$ & $\mathrm{Cy}$ & 24.2 & -42.7 \\
$\mathbf{3 d}$ & $\mathrm{Ph}$ & 14.2 & -40.5 \\
$\mathbf{3 e}$ & ${ }^{\mathrm{B} u}$ & 42.8 & -42.5 \\
\hline
\end{tabular}


Table S6. Selected NMR spectroscopic data for $\mathbf{6 e}+\mathbf{7 c / e}$

\begin{tabular}{cccccc}
\hline Compound & $\mathrm{R}=$ & $\delta_{\mathrm{P}} / \mathrm{ppm}$ & $\delta_{\mathrm{B}} / \mathrm{ppm}$ & $\begin{array}{c}\delta_{\mathrm{H}}(\mathrm{Fe}-\mathrm{H}) / \\
\mathrm{ppm}\end{array}$ & $\delta_{\mathrm{H}}(\mathrm{Fe}-\mathrm{HB}) / \mathrm{ppm}$ \\
\hline $\mathbf{6 e}$ & ${ }^{t} \mathrm{Bu}$ & $103.7(\mathrm{~s})$ & -21.9 & -15.85 & -10.29 \\
& & & & \\
$\mathbf{7 c}$ & $\mathrm{Cy}$ & $97.9(\mathrm{AB}-\mathrm{system})$ & $-11.8,-42.6$ & -14.60 & -11.17 \\
& & $J_{\mathrm{AB}}=118.6 \mathrm{~Hz}, \Delta v=963.7 \mathrm{~Hz}$ & & -17.65 \\
$\mathbf{7 e}$ & ${ }^{t} \mathrm{Bu}$ & $118.2(\mathrm{AB}-\mathrm{system})$ & $-11.9,-42.5$ & -14.93 & -10.49 \\
& & $J_{\mathrm{AB}}=119.0 \mathrm{~Hz}, \Delta v=624.7 \mathrm{~Hz}$ & & -14.55 & \\
$\mathbf{9 c}$ & $\mathrm{Cy}$ & $101.3(\mathrm{AB}-$ system $)$ & -16.2 & & \\
& & $J_{\mathrm{AB}}=118.6 \mathrm{~Hz}, \Delta v=199.7 \mathrm{~Hz}$ & &
\end{tabular}

\section{NMR spectra}

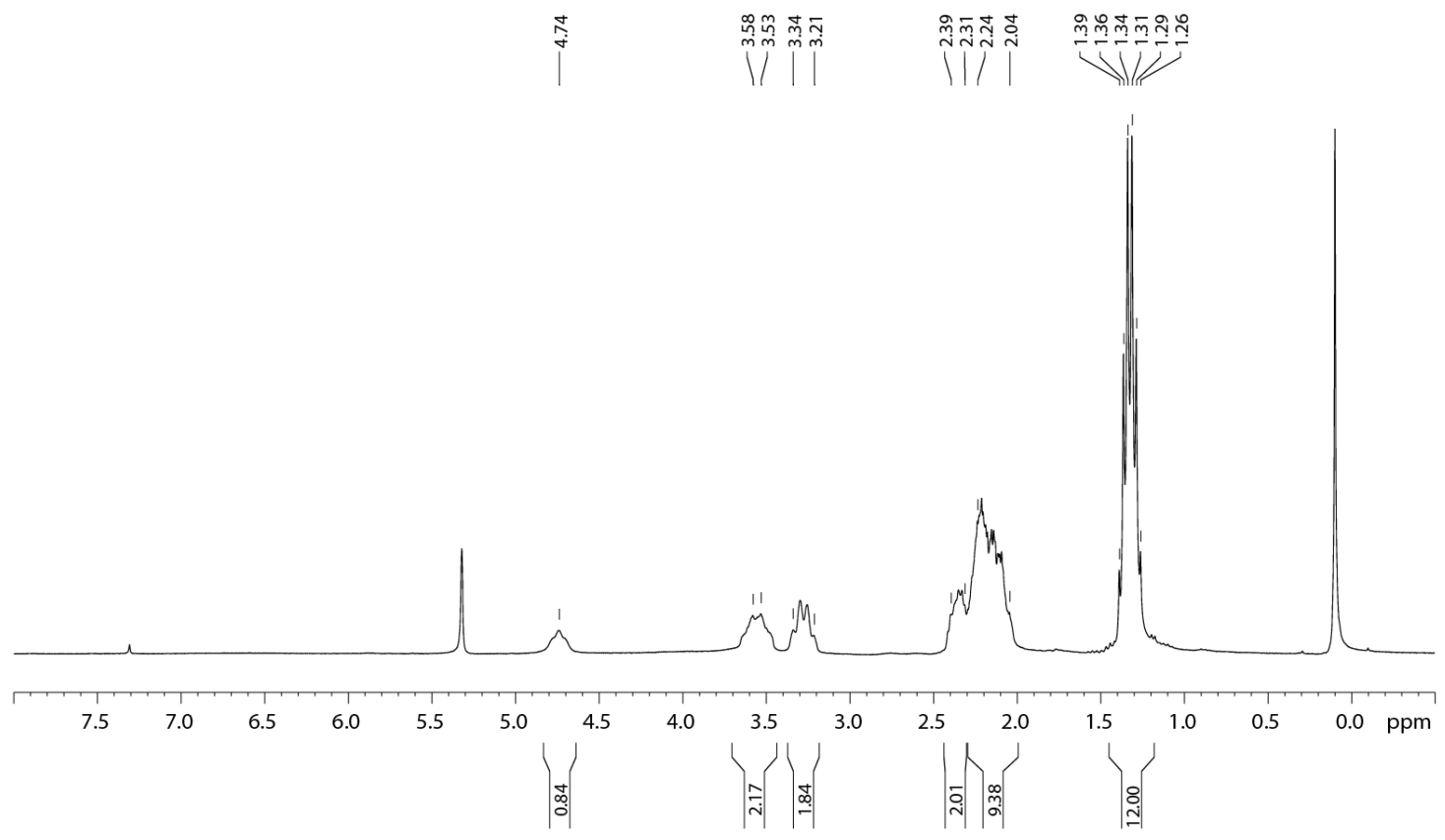

Figure 1. ${ }^{l} \mathrm{H}$ NMR spectrum of complex 1 a in $\mathrm{CD}_{2} \mathrm{Cl}_{2}$. 


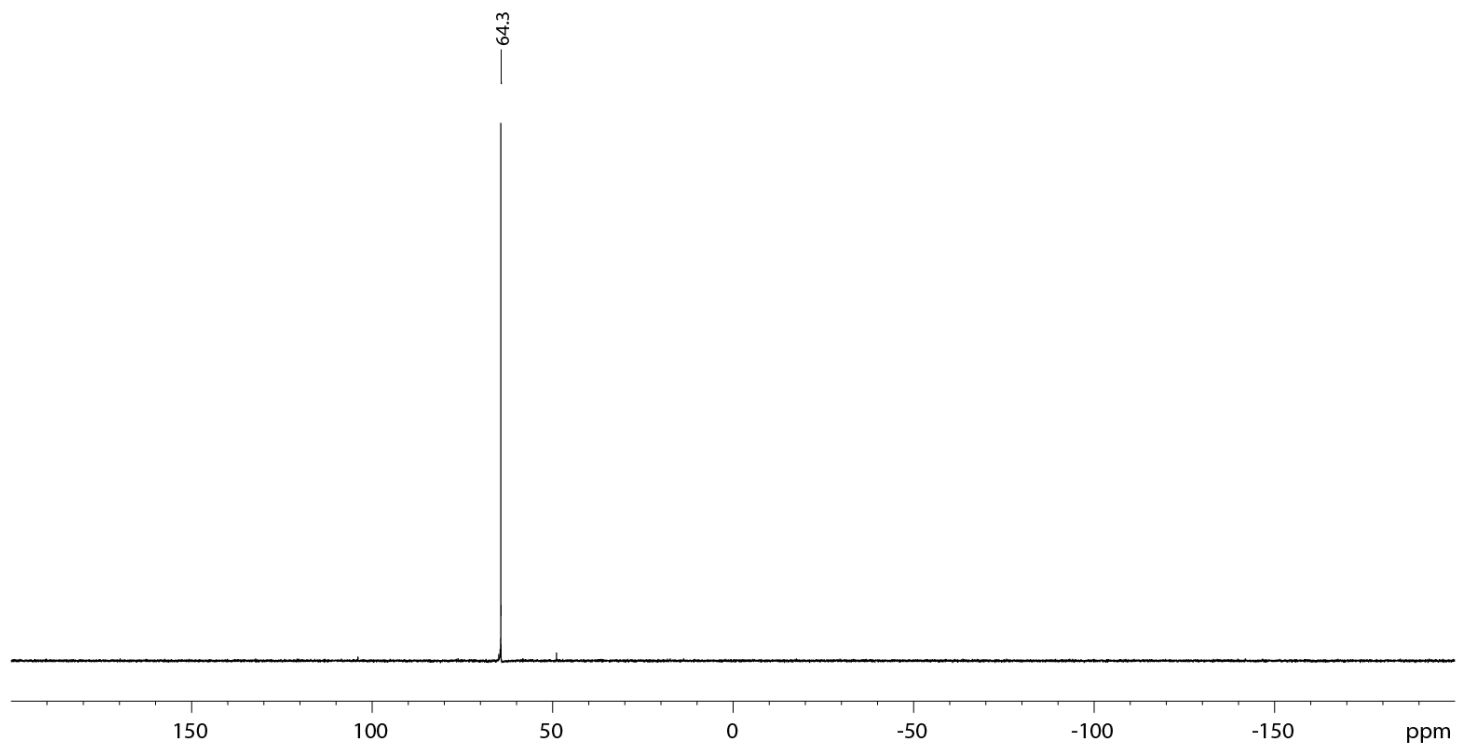

Figure 2. ${ }^{31} \mathrm{P}\left\{{ }^{1} \mathrm{H}\right\} \mathrm{NMR}$ spectrum of complex 1 a in $\mathrm{CD}_{2} \mathrm{Cl}_{2}$.

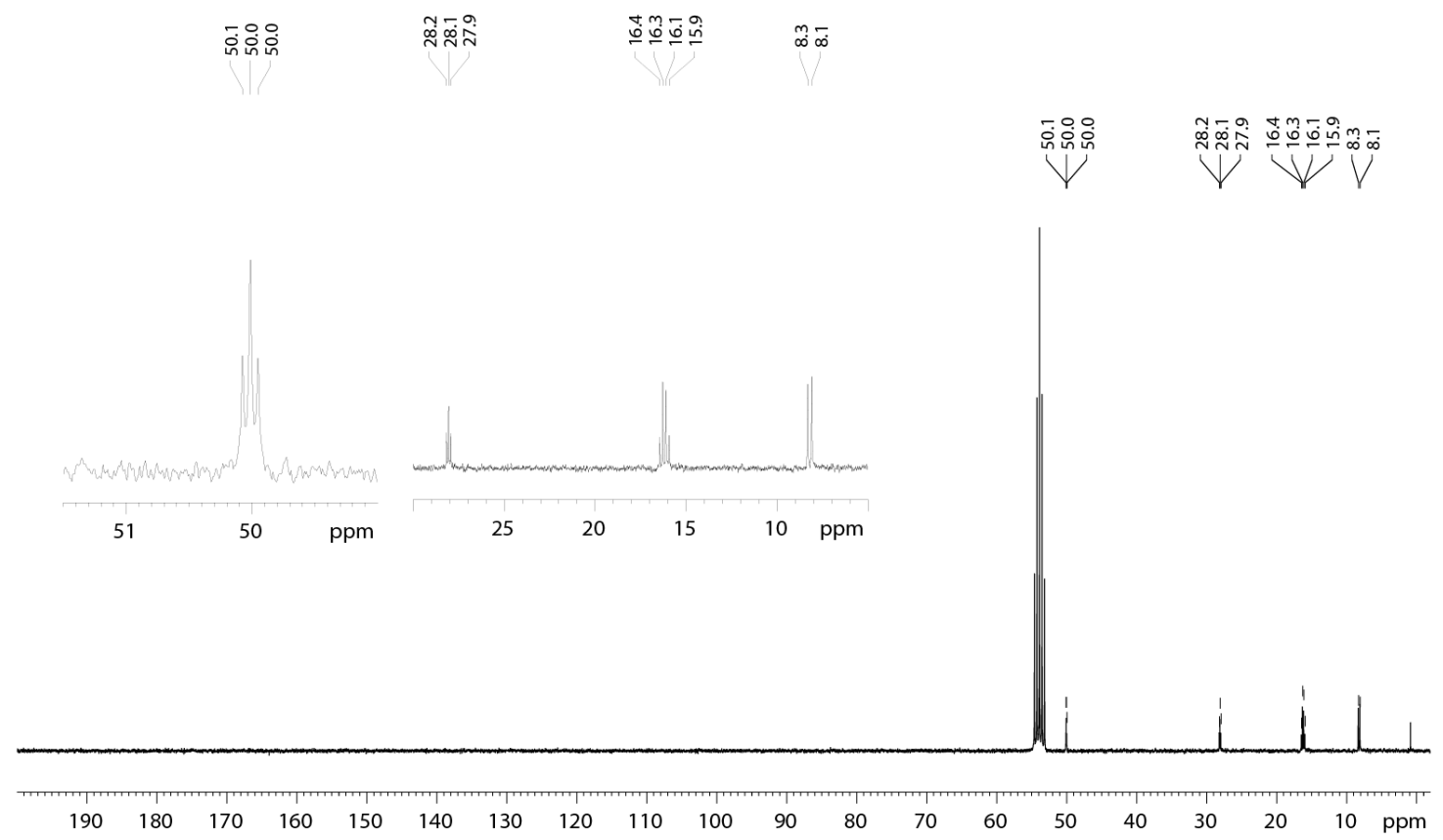

Figure 3. ${ }^{13} \mathrm{C}\left\{{ }^{1} \mathrm{H}\right\} \mathrm{NMR}$ spectrum of complex $1 \mathrm{a}$ in $\mathrm{CD}_{2} \mathrm{Cl}_{2}$. 


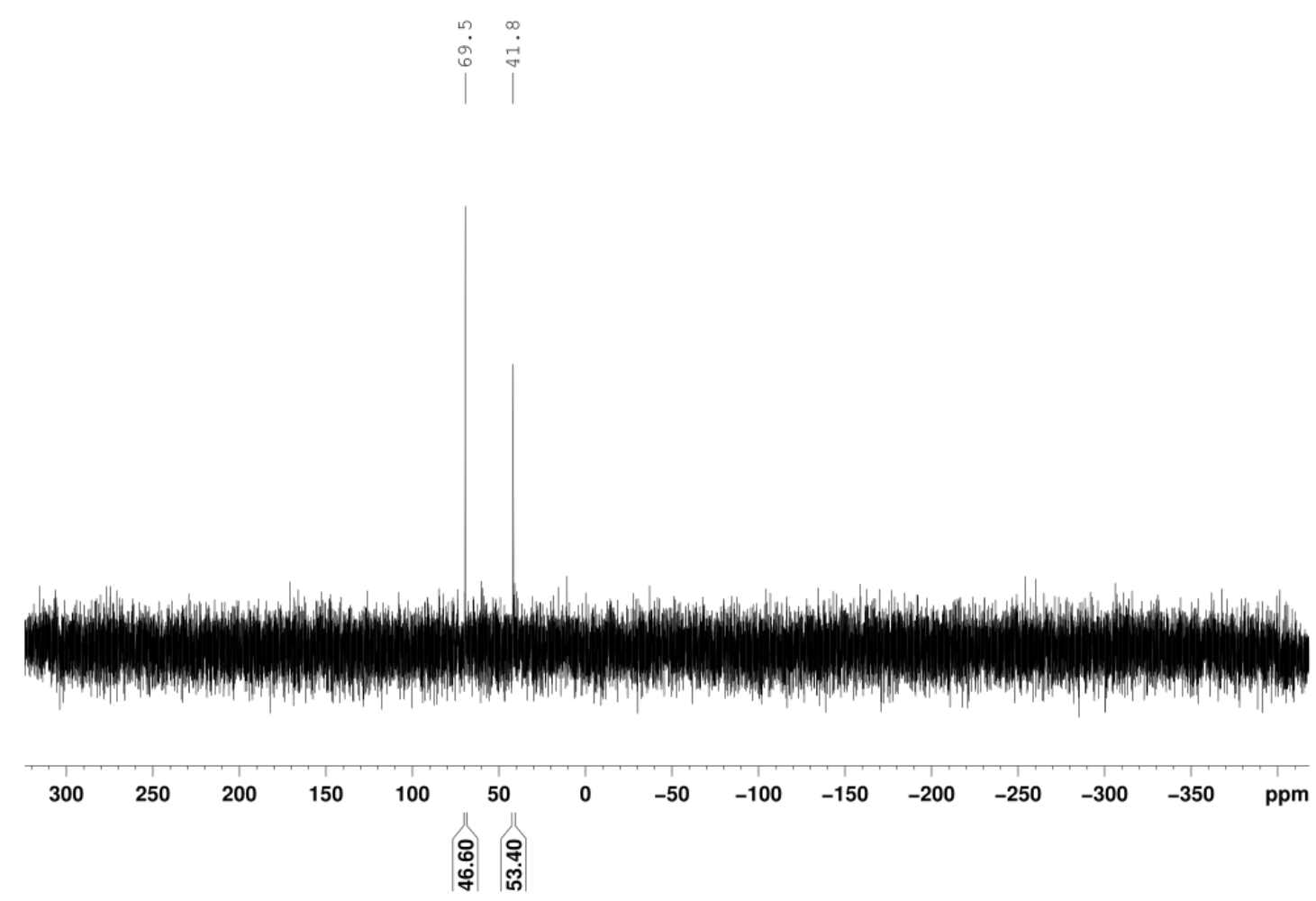

Figure 4. ${ }^{31} \mathrm{P}\left\{{ }^{1} \mathrm{H}\right\}$ NMR spectrum of complex $1 \mathrm{~d}$ in $\mathrm{CD}_{2} \mathrm{Cl}_{2}$.

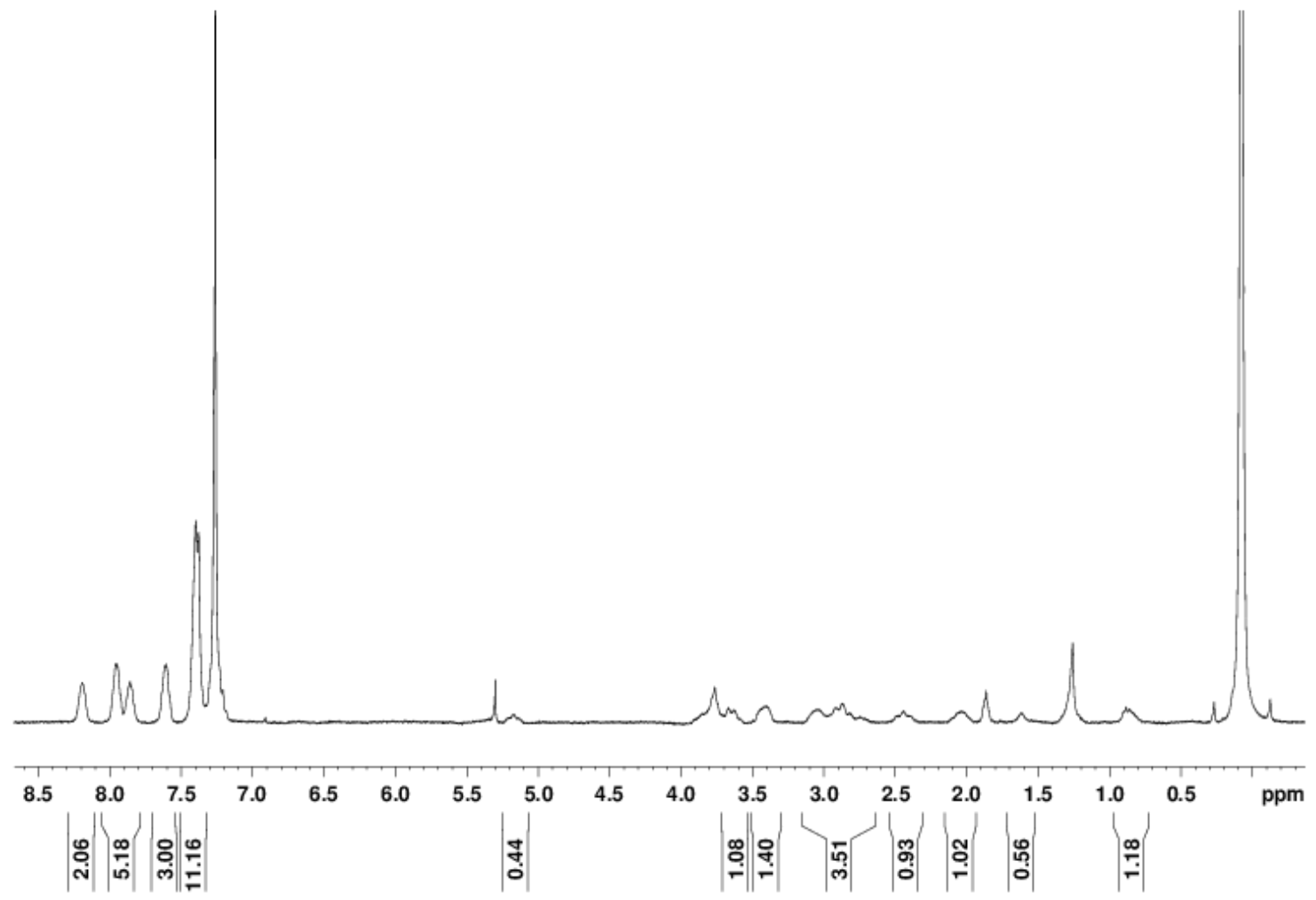

Figure 5. ${ }^{1} \mathrm{H}$ NMR spectrum of complex 1 d in $\mathrm{CDCl}_{3}$. 

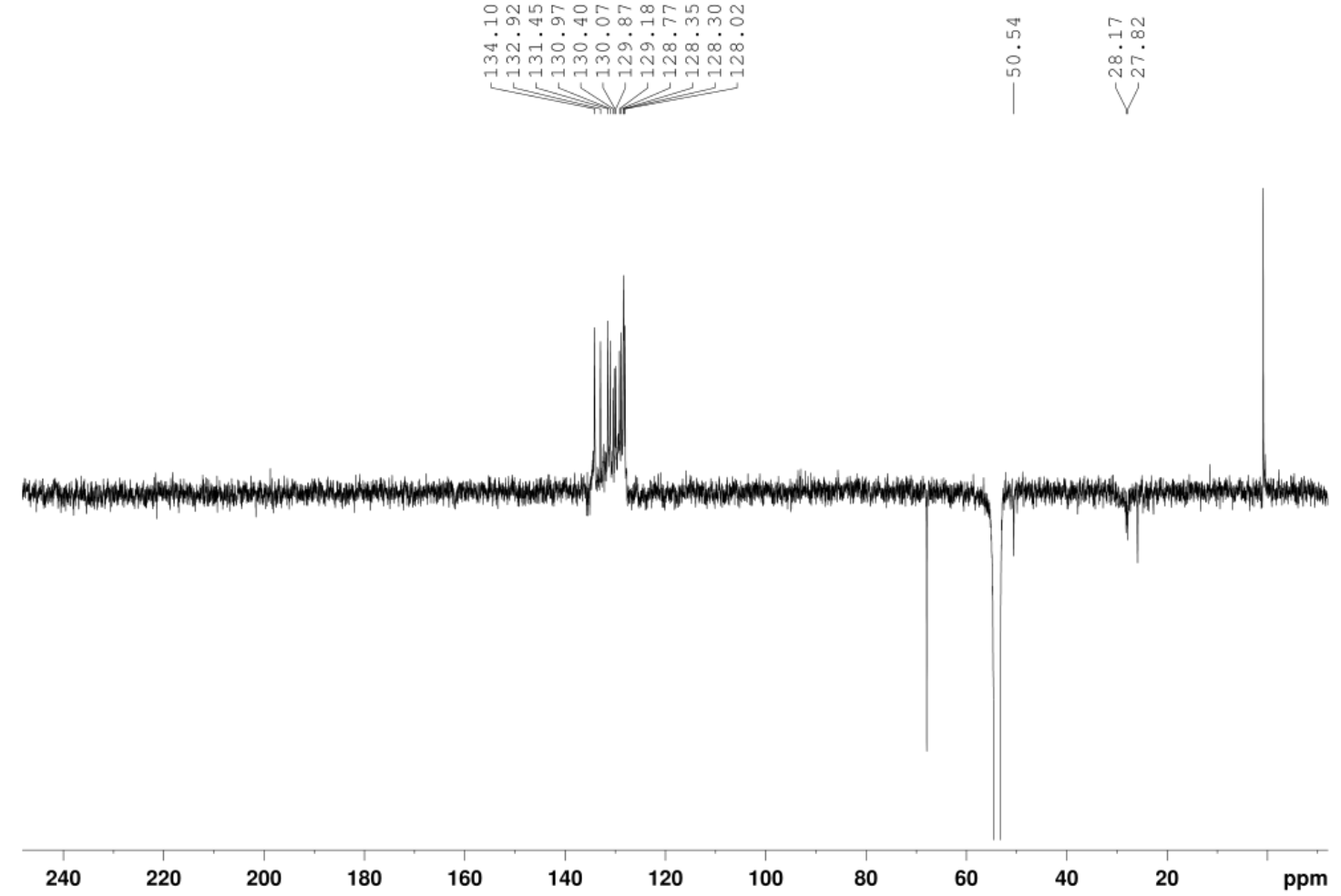

Figure 6. ${ }^{13} \mathrm{C}$-APT NMR spectrum of complex $1 \mathrm{~d}$ in $\mathrm{CD}_{2} \mathrm{Cl}_{2}$.

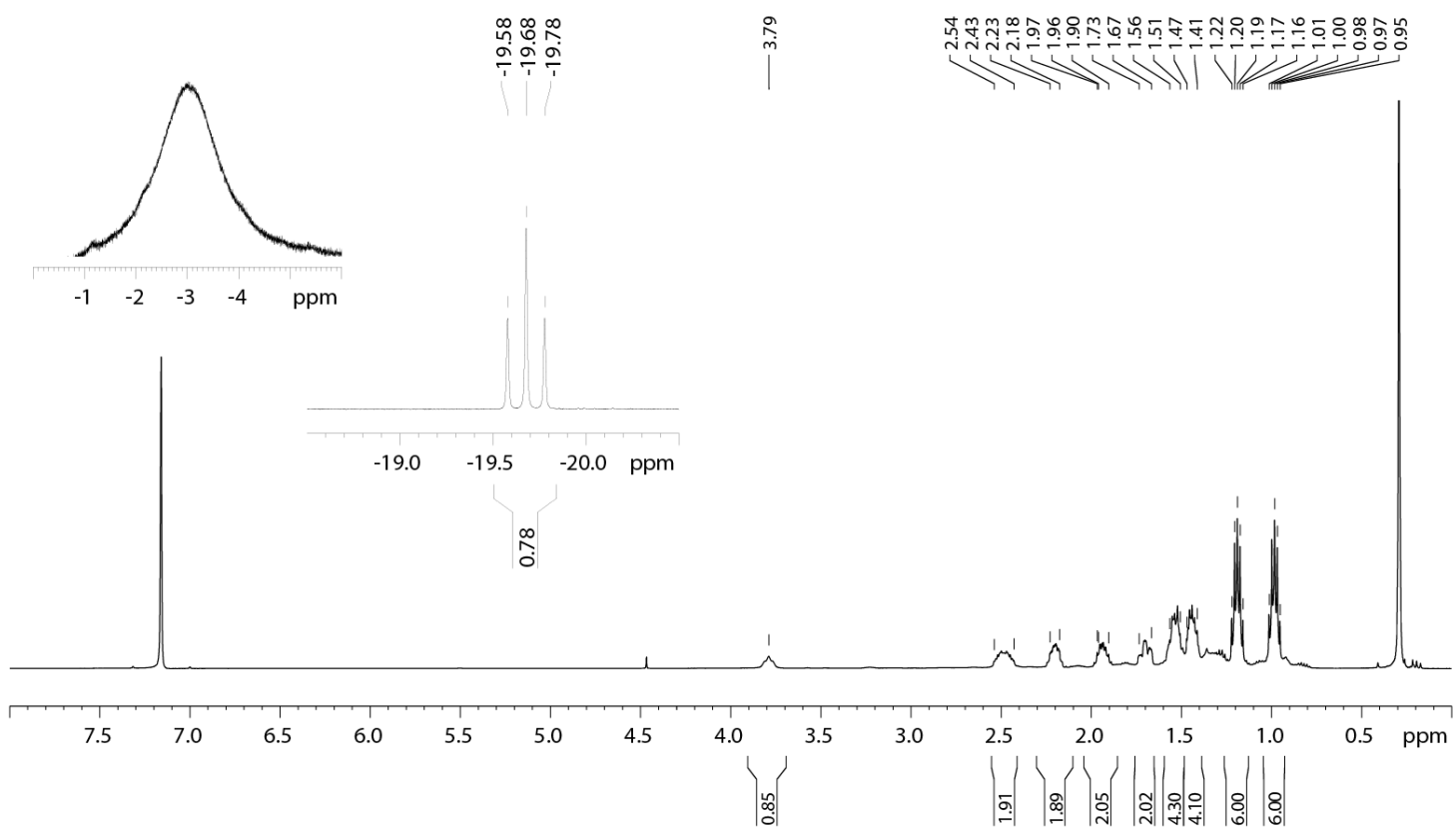

Figure 7. ${ }^{1} H$ NMR spectrum of complex $2 a$ in $C_{6} D_{6}$. 


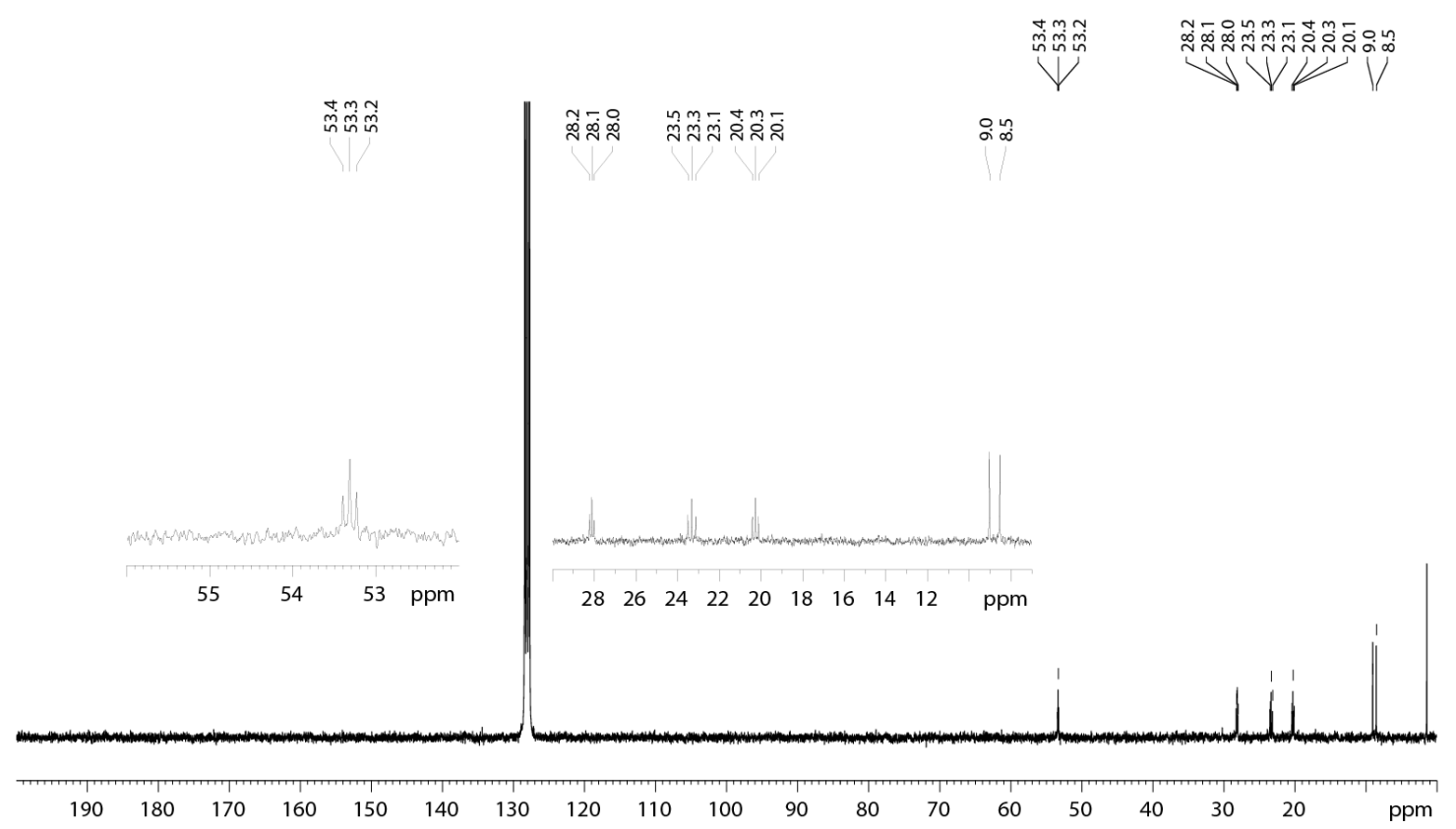

Figure $8 .{ }^{13} C\left\{{ }^{1} H\right\}$ NMR spectrum of complex $2 a$ in $C_{6} D_{6}$.

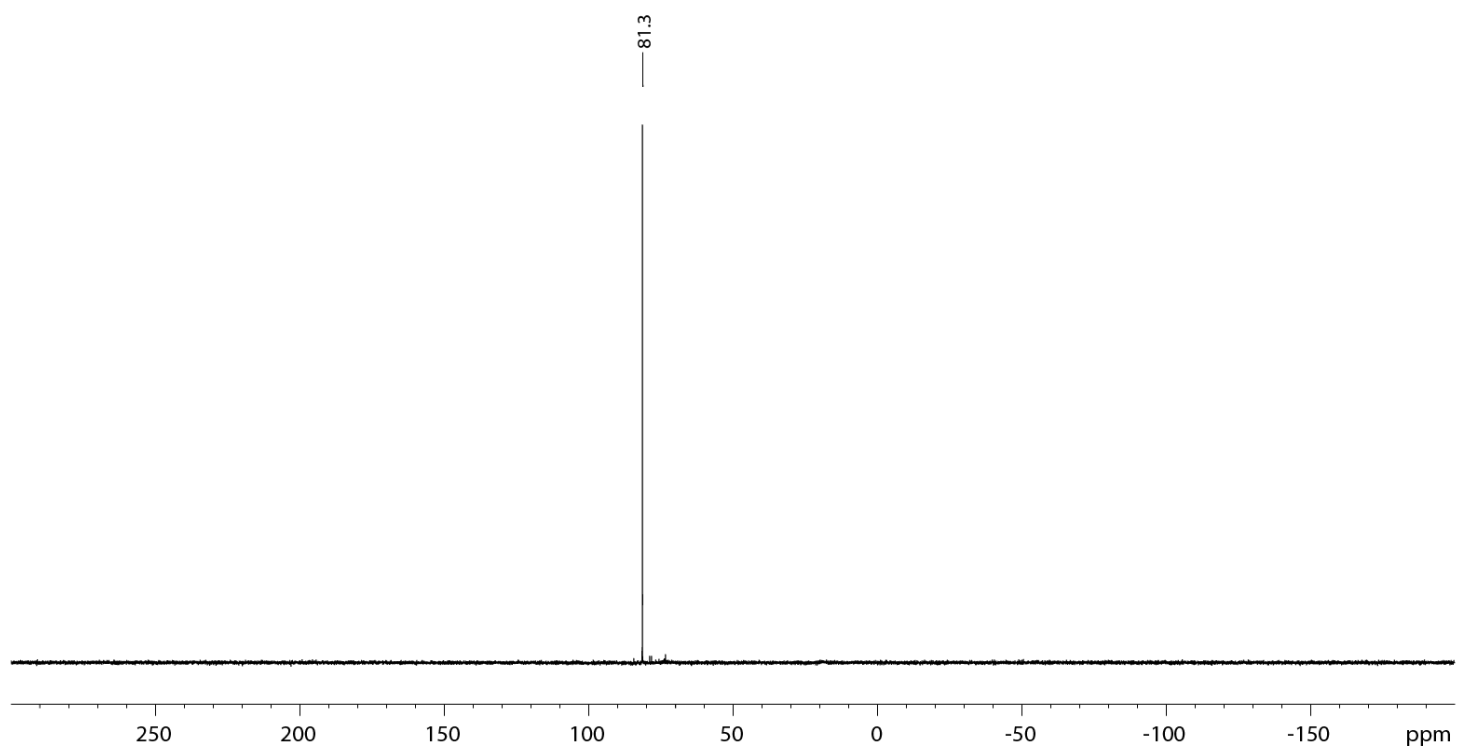

Figure 9. ${ }^{31} P\left\{{ }^{1} H\right\}$ NMR spectrum of complex $2 a$ in $C_{6} D_{6}$. 


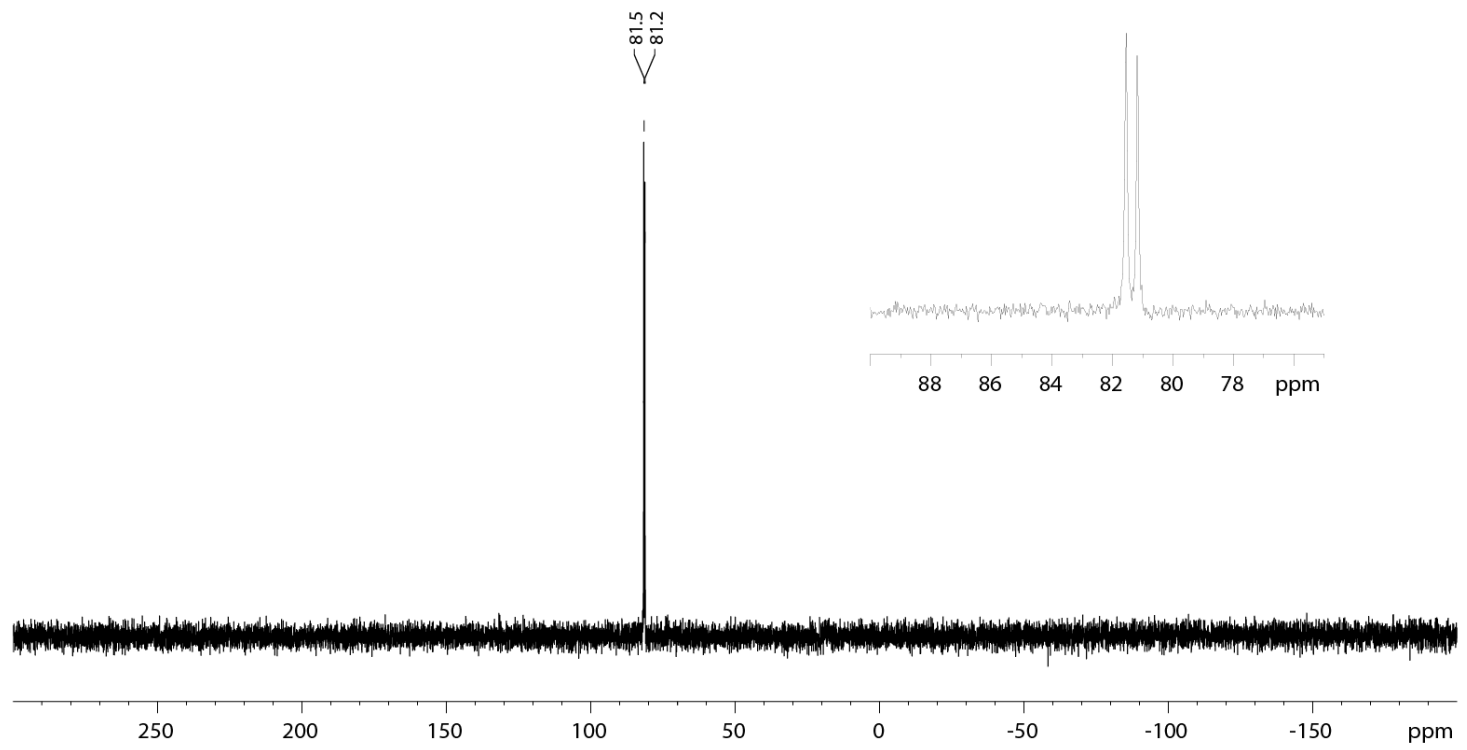

Figure 10. ${ }^{31} P$ NMR spectrum of complex $2 a$ in $C_{6} D_{6}$.
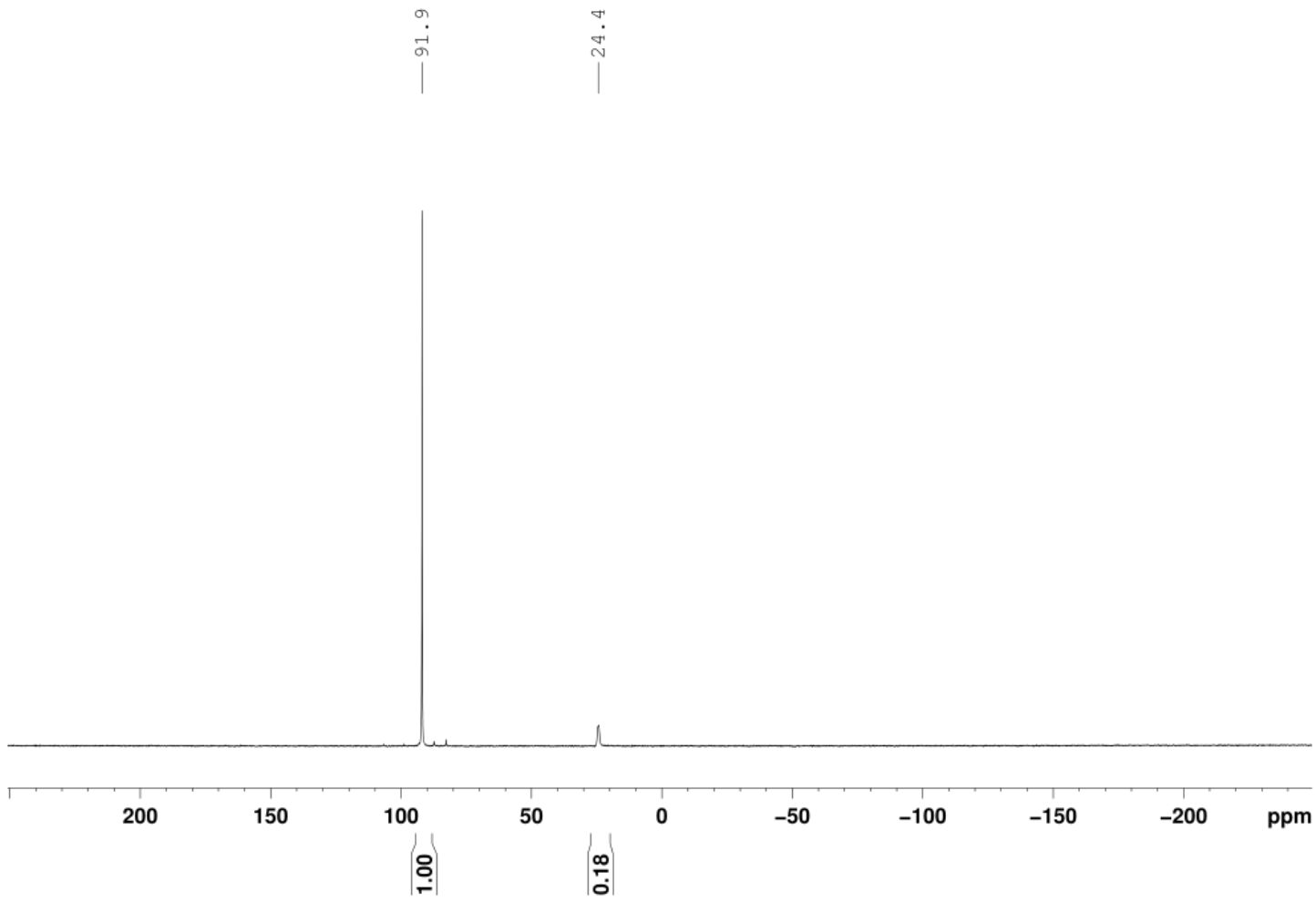

Figure 11. ${ }^{31} P\left\{{ }^{1} H\right\}$ NMR spectrum of complex $2 c$ in $C_{6} D_{6}$. 


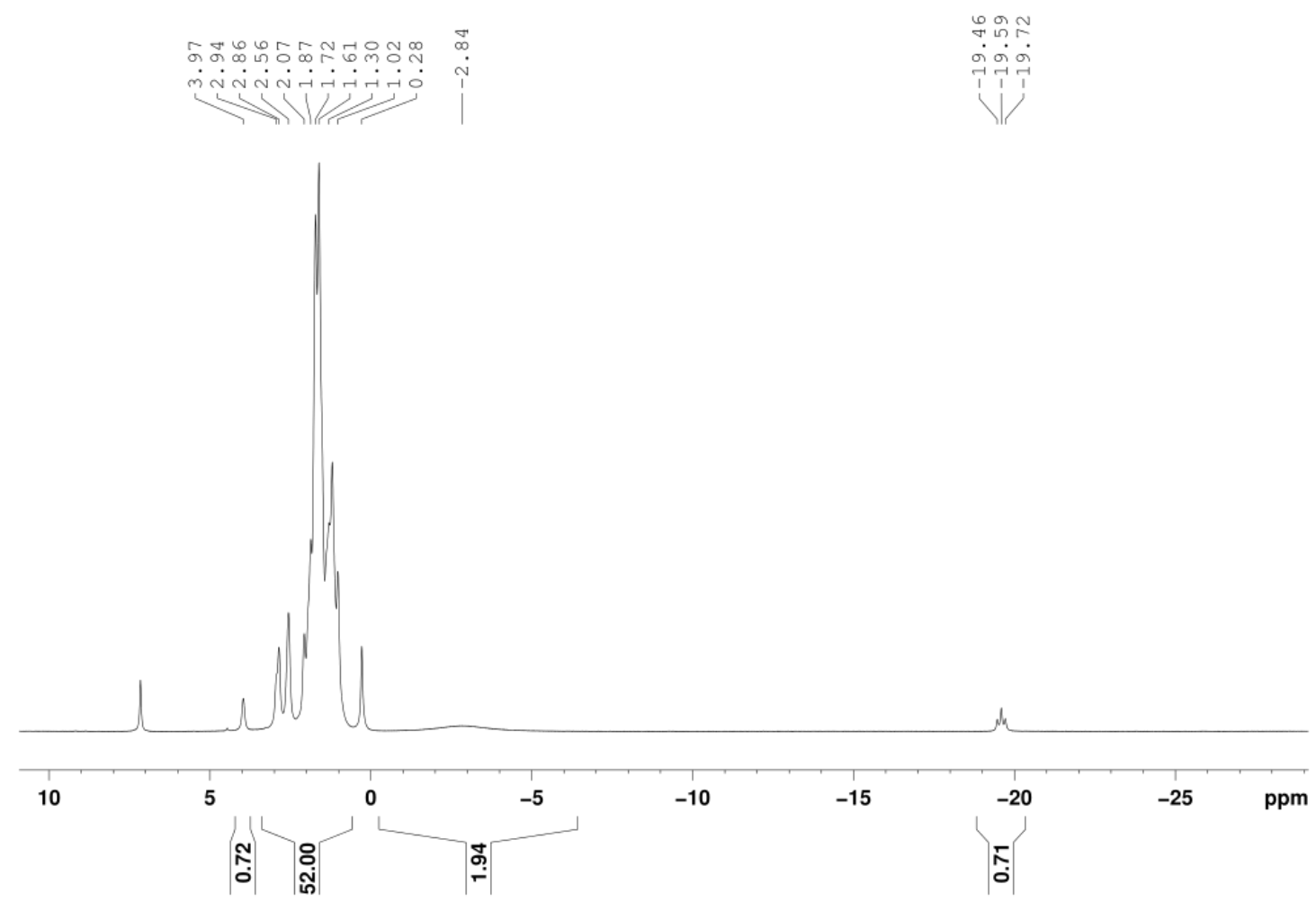

Figure 12. ${ }^{1} \mathrm{H}$ NMR spectrum of complex $2 \boldsymbol{c}$ in $C_{6} D_{6}$ containing $3 c$.

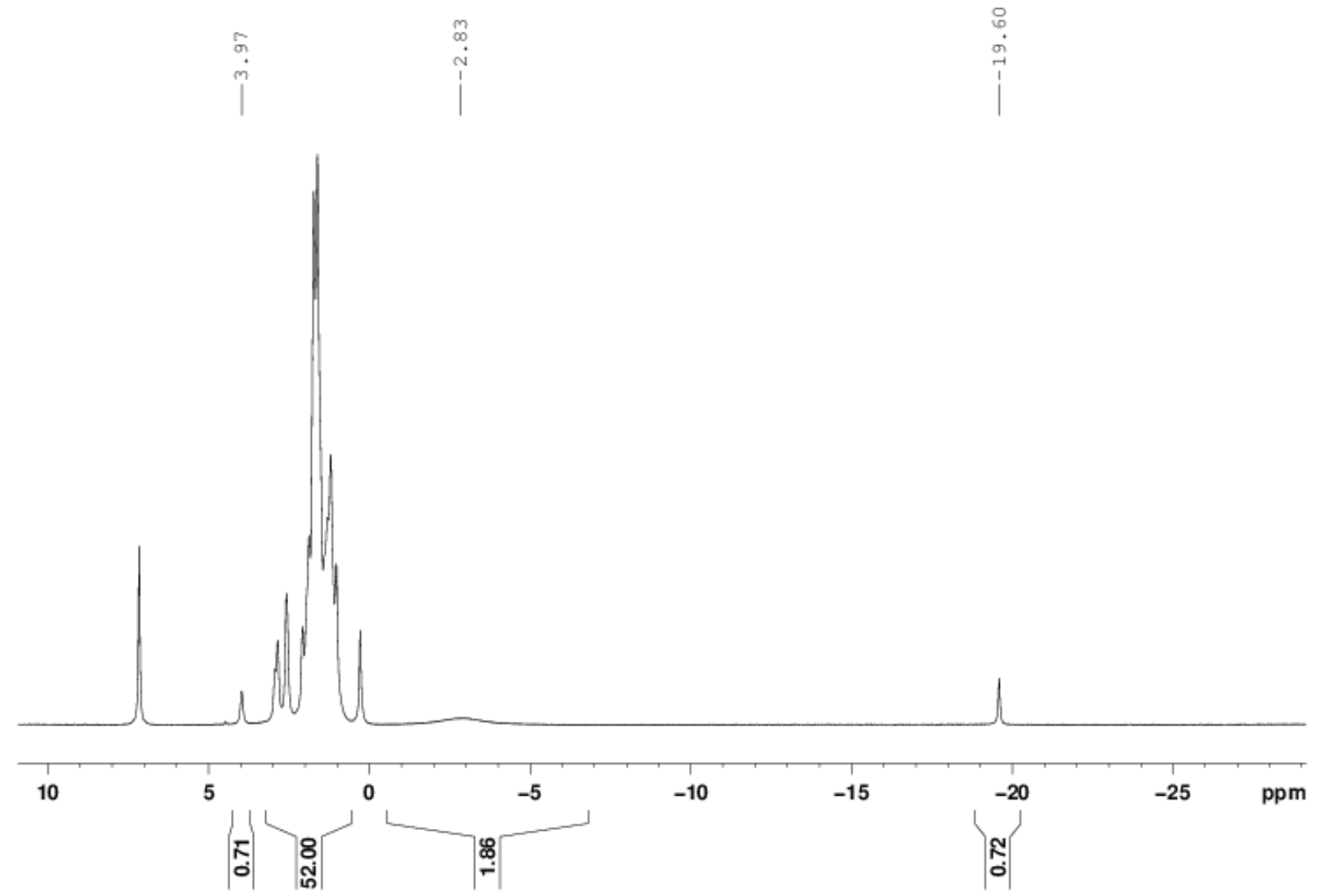

Figure 13. ${ }^{1} H\left\{{ }^{31} P\right\}$ NMR spectrum of complex $2 c$ in $C_{6} D_{6}$ containing $3 c$. 

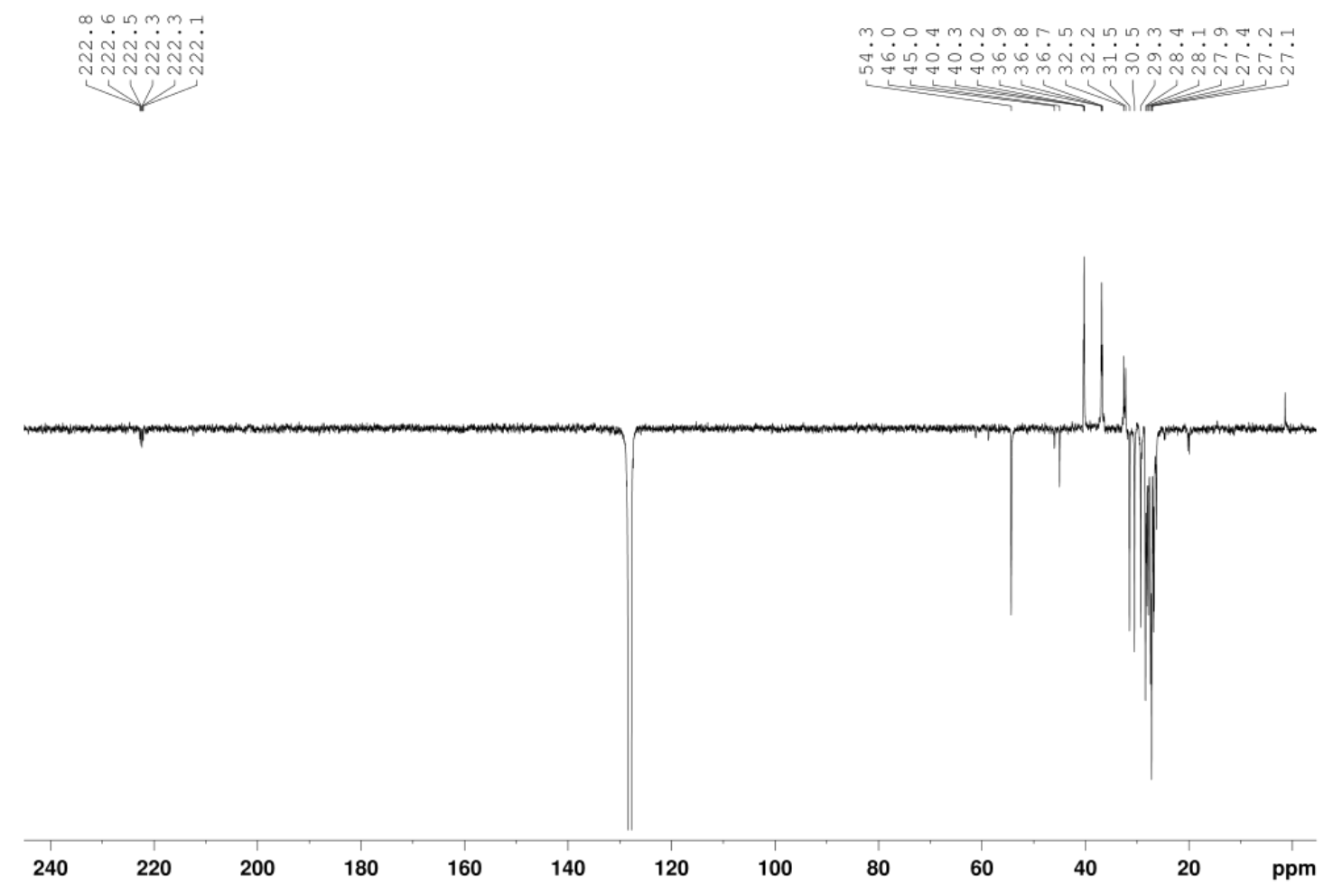

Figure 14. ${ }^{13} C$-APT NMR spectrum of complex $2 c$ in $C_{6} D_{6}$ containing $3 \boldsymbol{c}$.
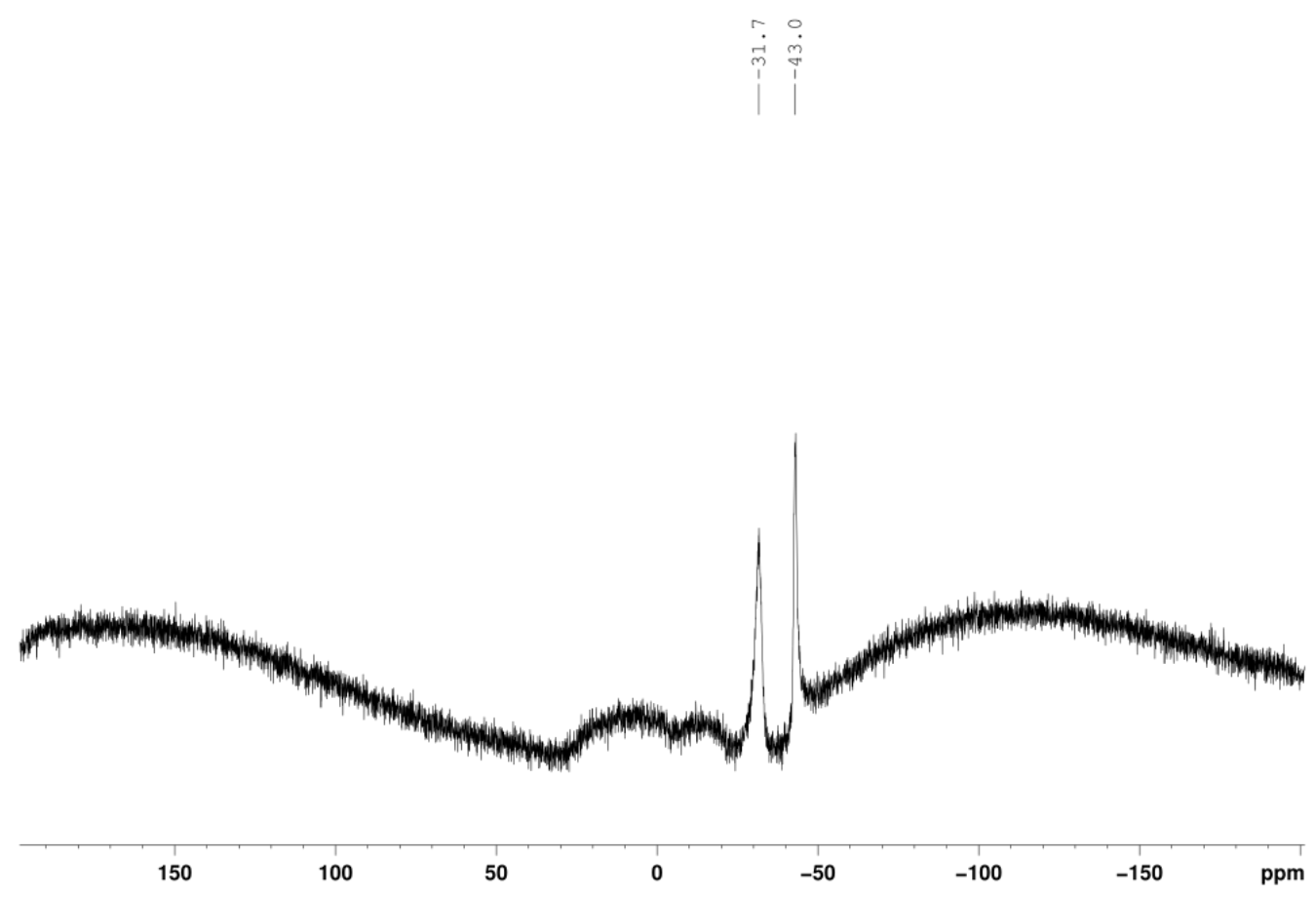

Figure 15. ${ }^{11} B\left\{{ }^{1} H\right\} N M R$ spectrum of complex $2 c$ in $C_{6} D_{6}$ containing $3 c$. 


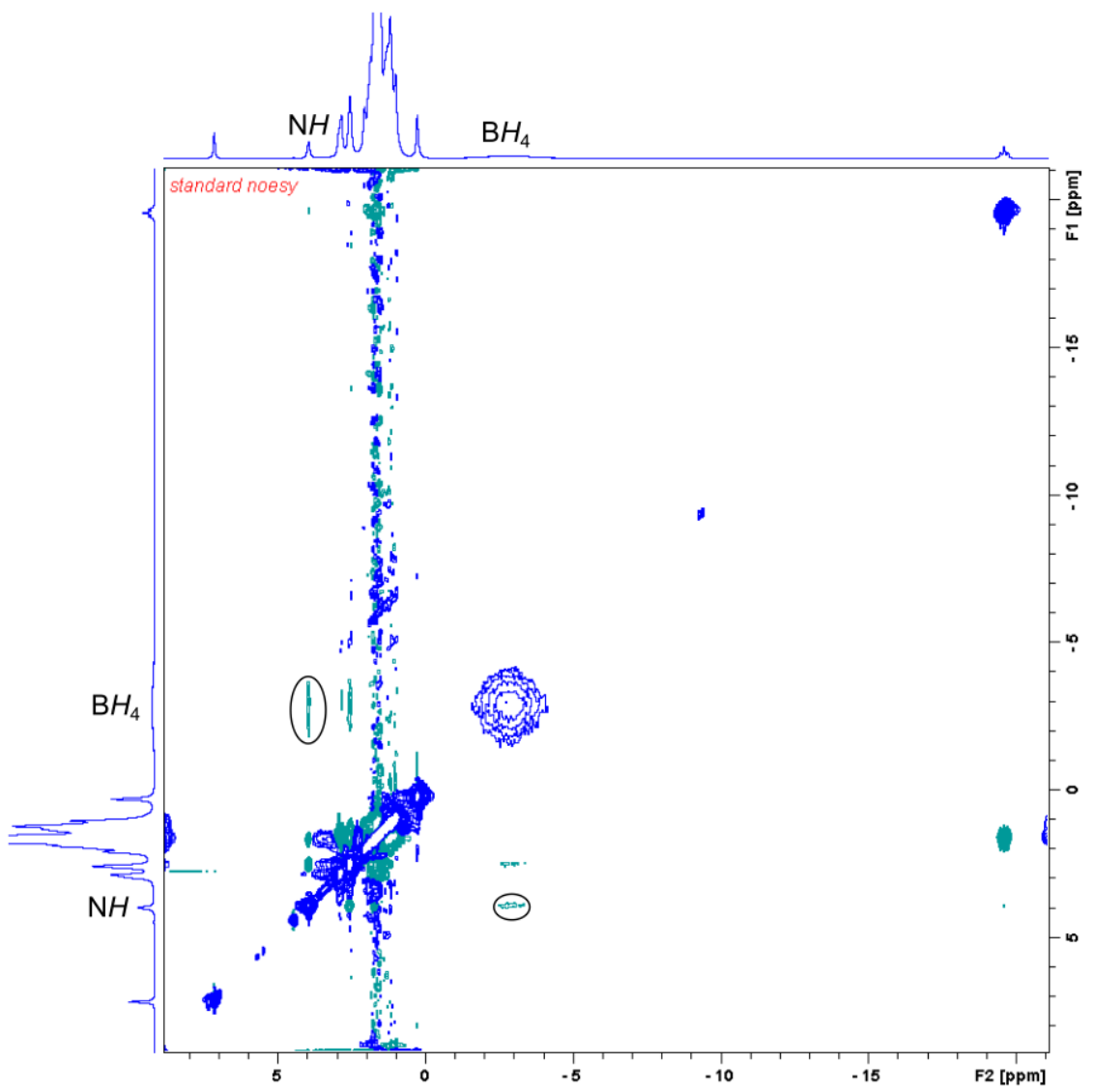

Figure 16. ${ }^{1} \mathrm{H}$ NOESY NMR spectrum of complex $2 \mathrm{c}$ in $C_{6} D_{6}$ containing $3 c$.

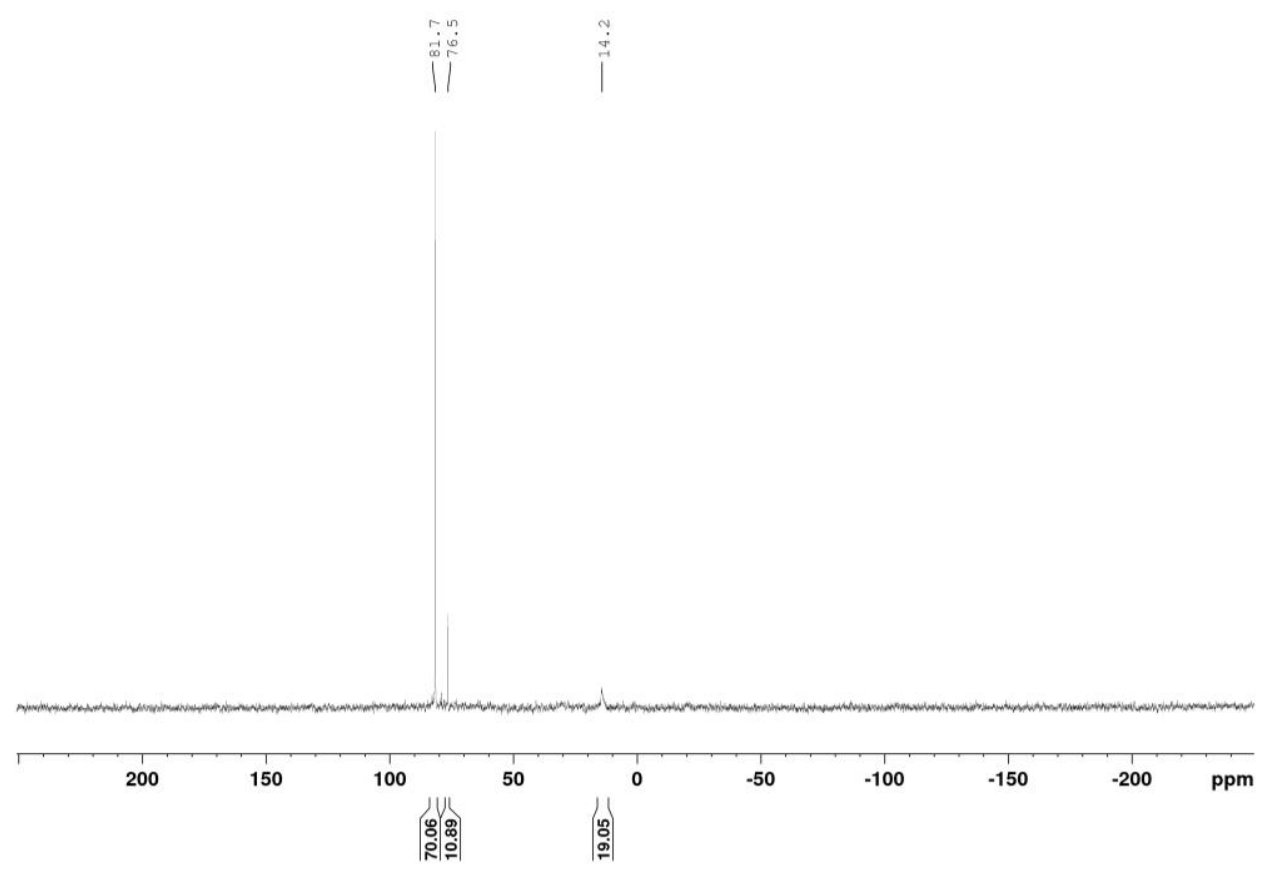

Figure 17. ${ }^{31} \mathrm{P}\left\{{ }^{1} \mathrm{H}\right\}$ NMR spectrum of complex $2 \boldsymbol{d}$ in $\mathrm{CD}_{2} \mathrm{Cl}_{2}$ containing $\mathbf{3 d}$. 


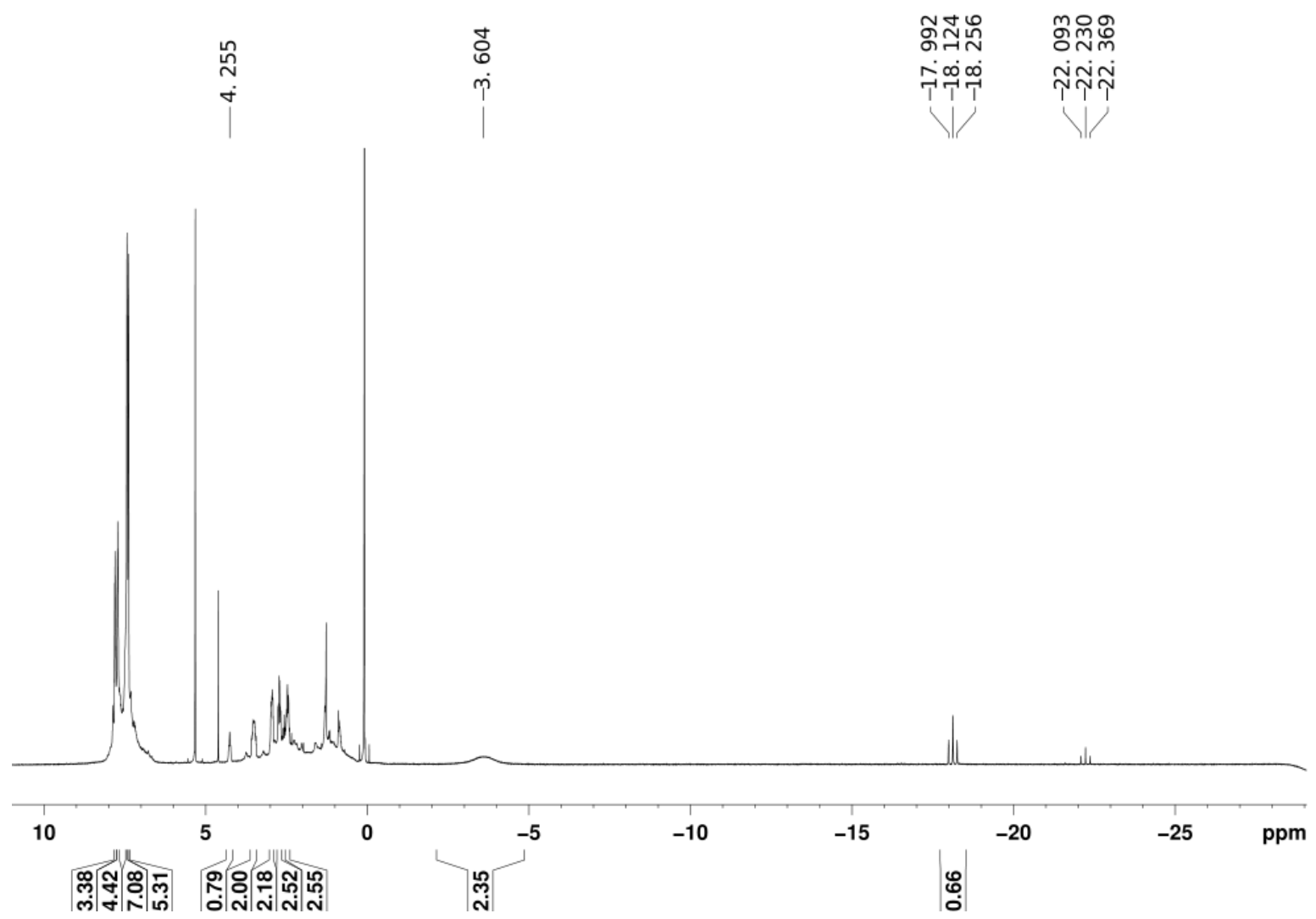

Figure 18. ${ }^{1} \mathrm{H}$ NMR spectrum of complex $2 d$ in $\mathrm{CD}_{2} \mathrm{Cl}_{2}$ containing $3 d$. ตกเ

ஸ்றுł

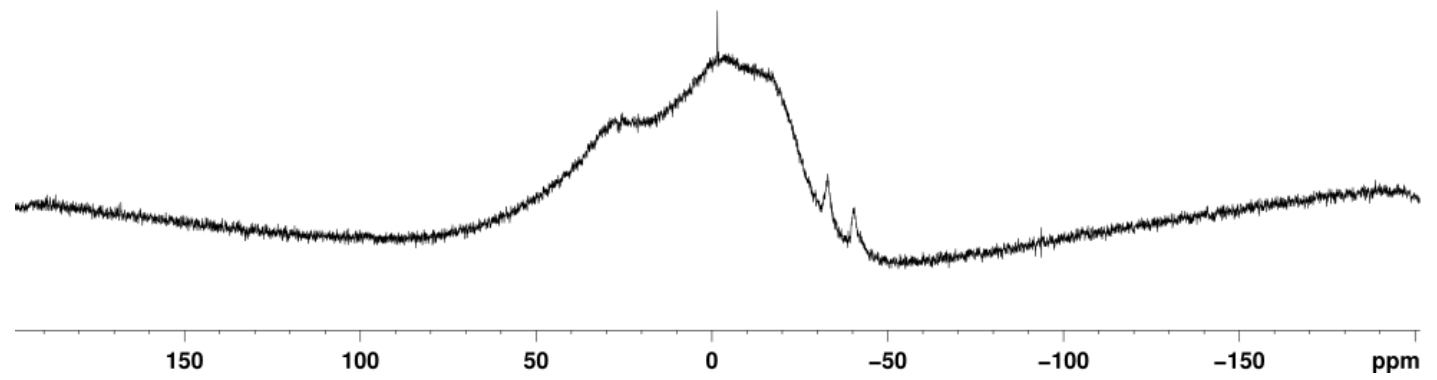

Figure 19. ${ }^{11} B\left\{{ }^{l} H\right\}$ NMR spectrum of complex $2 d$ in $\mathrm{CD}_{2} \mathrm{Cl}_{2}$ containing $3 d$. 


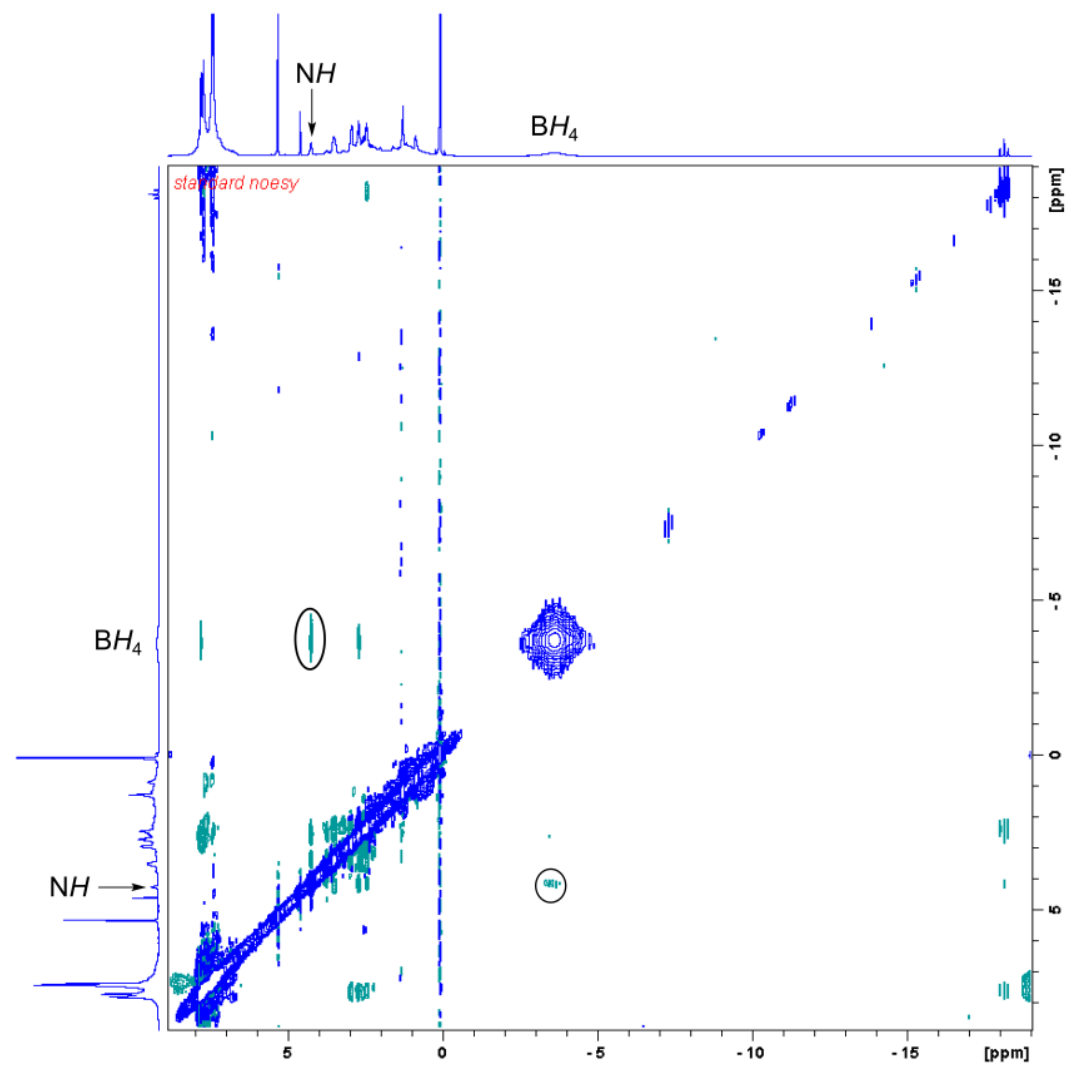

Figure 20. NOESY NMR spectrum of complex $2 \boldsymbol{d}$ in $\mathrm{CD}_{2} \mathrm{Cl}_{2}$ containing $\mathbf{3 d}$.

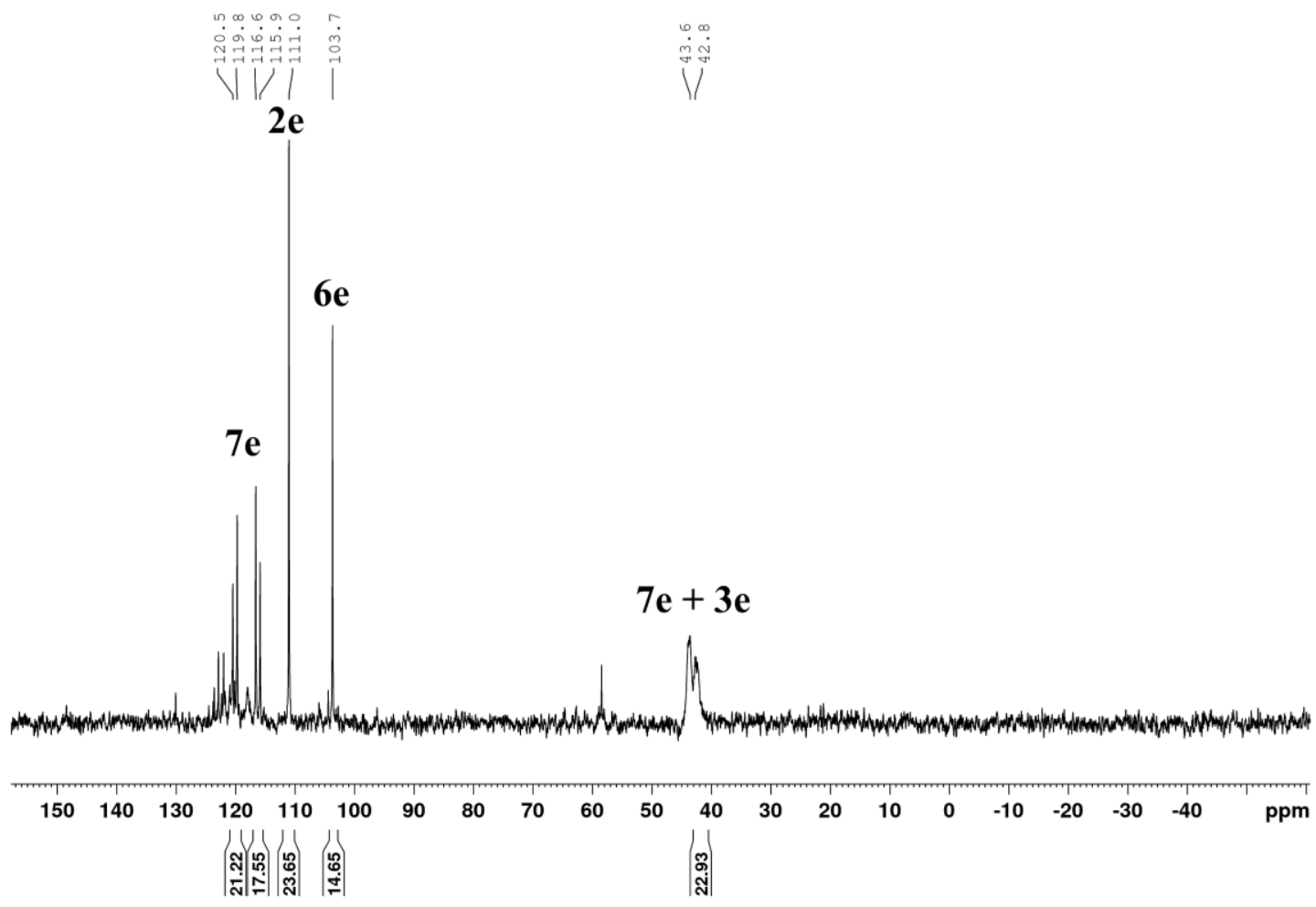

Figure 21. ${ }^{31} P\left\{{ }^{1} H\right\} N M R$ spectrum of the mixture of products in the attempted synthesis of $2 \boldsymbol{e}$. 


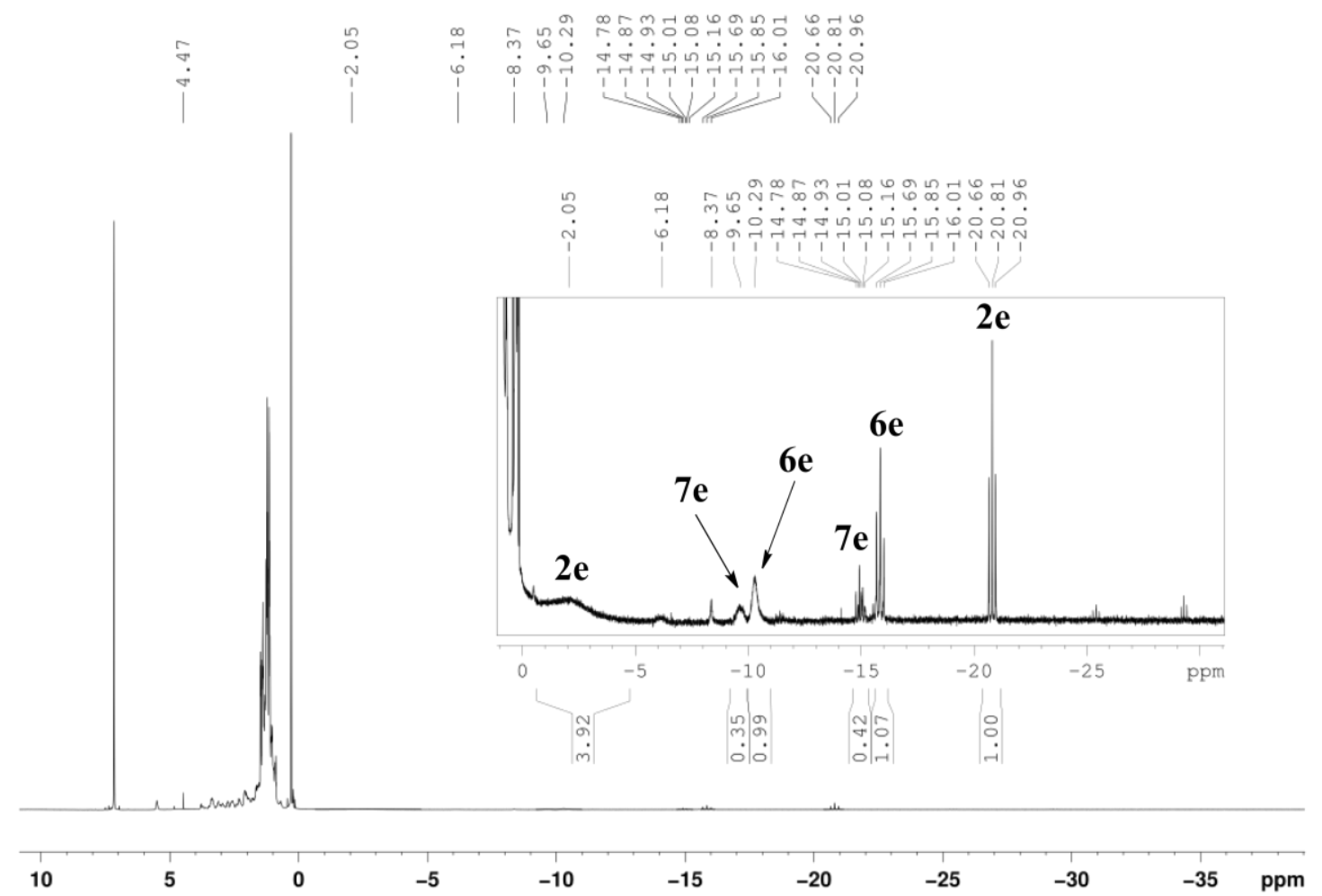

Figure 22. ${ }^{1} \mathrm{H}$ NMR spectrum of the mixture of products in the attempted synthesis of $2 \boldsymbol{e}$.
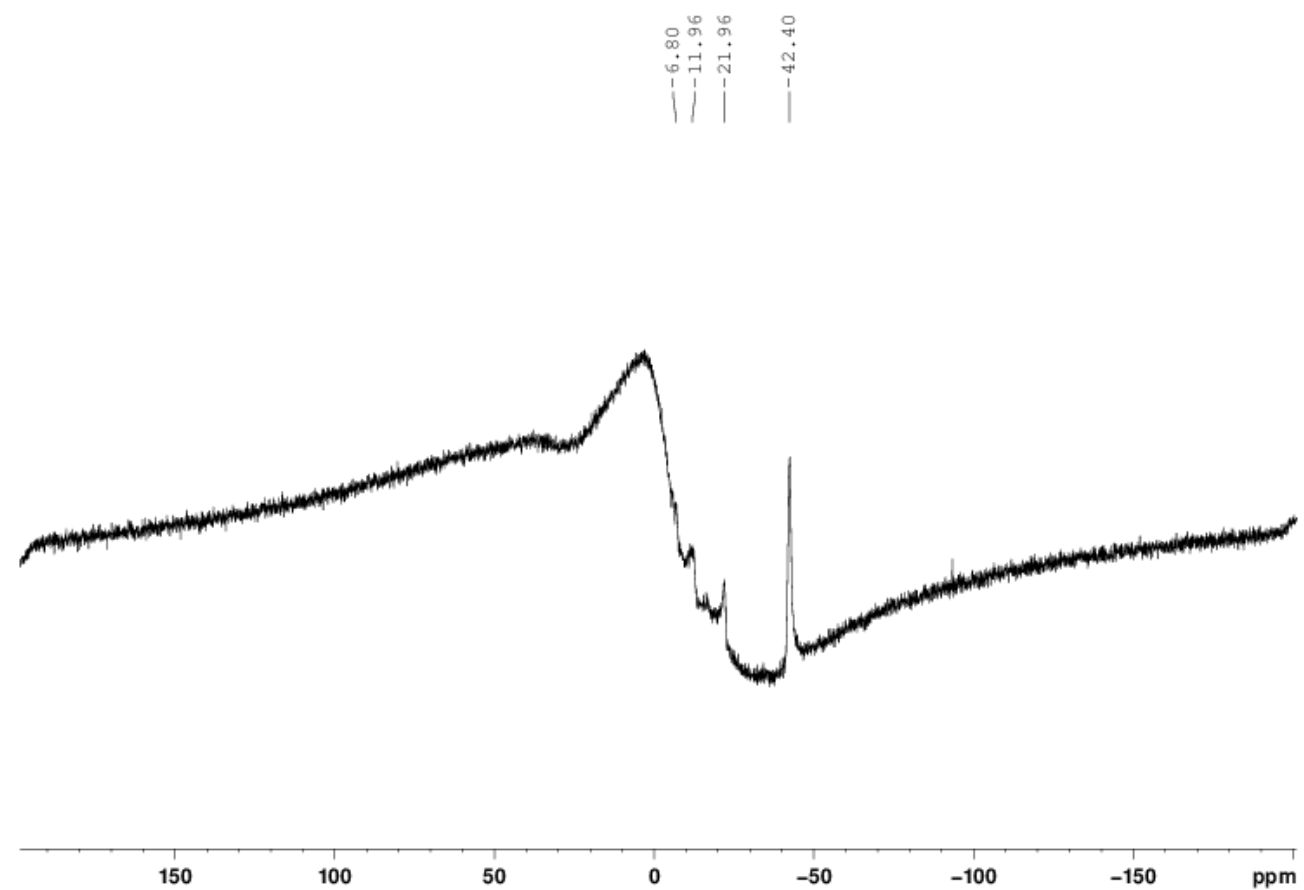

Figure 23. ${ }^{11} B\left\{{ }^{1} H\right\}$ NMR spectrum of the mixture of products in the attempted synthesis of $2 \boldsymbol{e}$. 


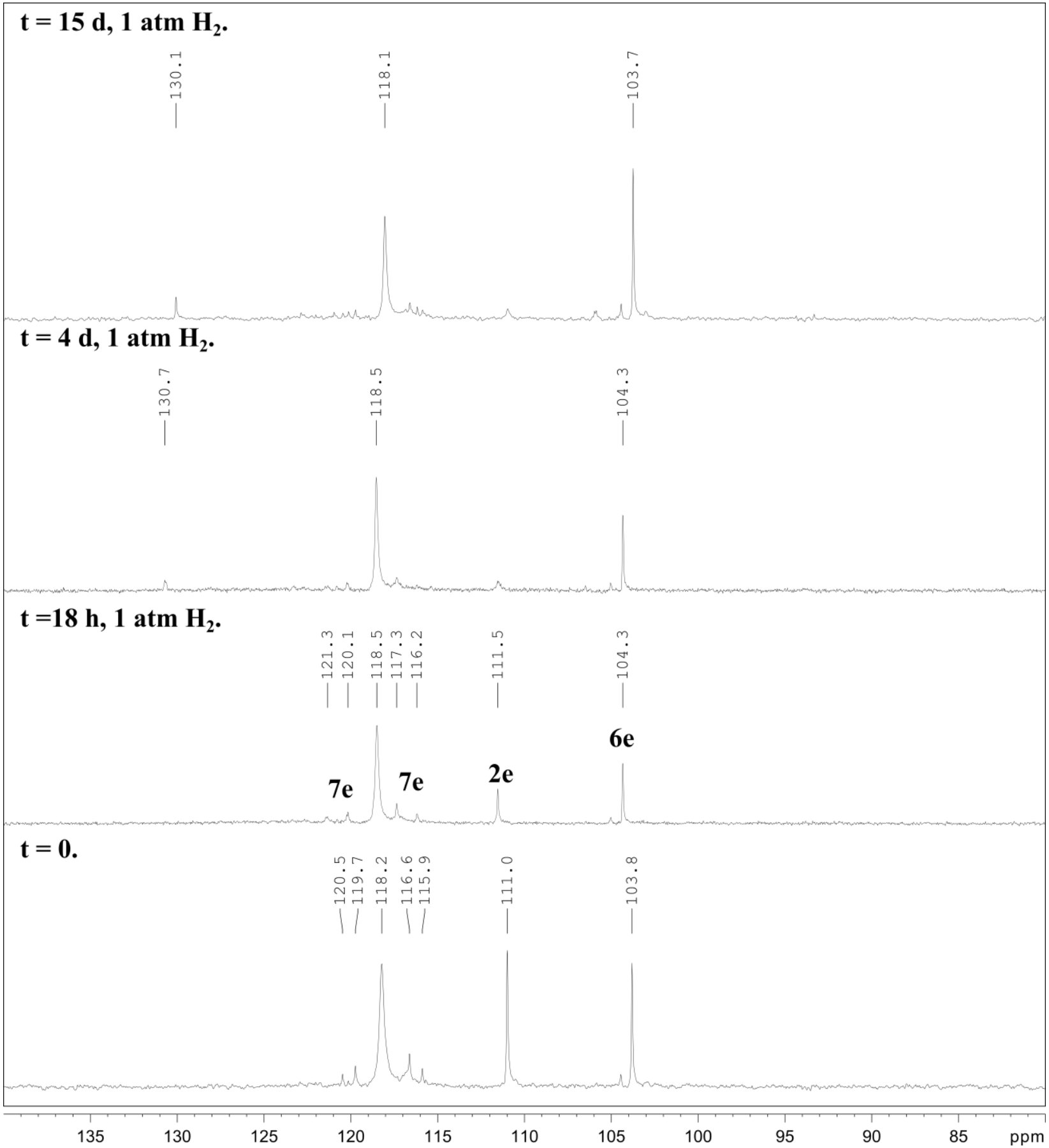

Figure 24. ${ }^{31} P\left\{{ }^{1} H\right\} N M R$ spectrum of the mixture of products, obtained in the attempted synthesis of $2 e$ after washing with $n$-hexane and exposition to 1 atm. of $\mathrm{H}_{2}$. 

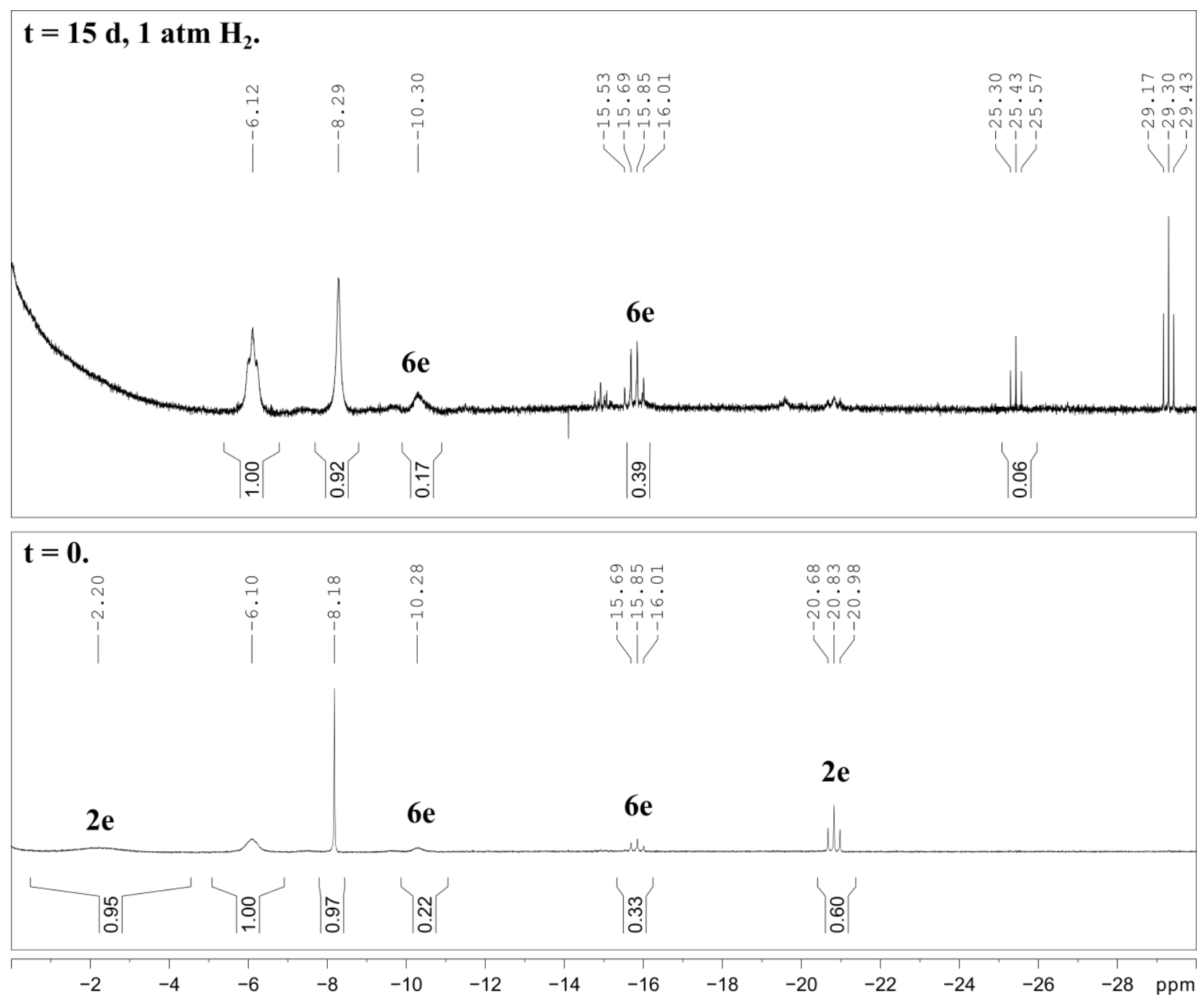

Figure 25. ${ }^{1} \mathrm{H}$ NMR spectrum of the mixture of products, obtained in the attempted synthesis of $2 e$ after washing with n-hexane and exposition to $1 \mathrm{~atm}$. of $\mathrm{H}_{2}$. 


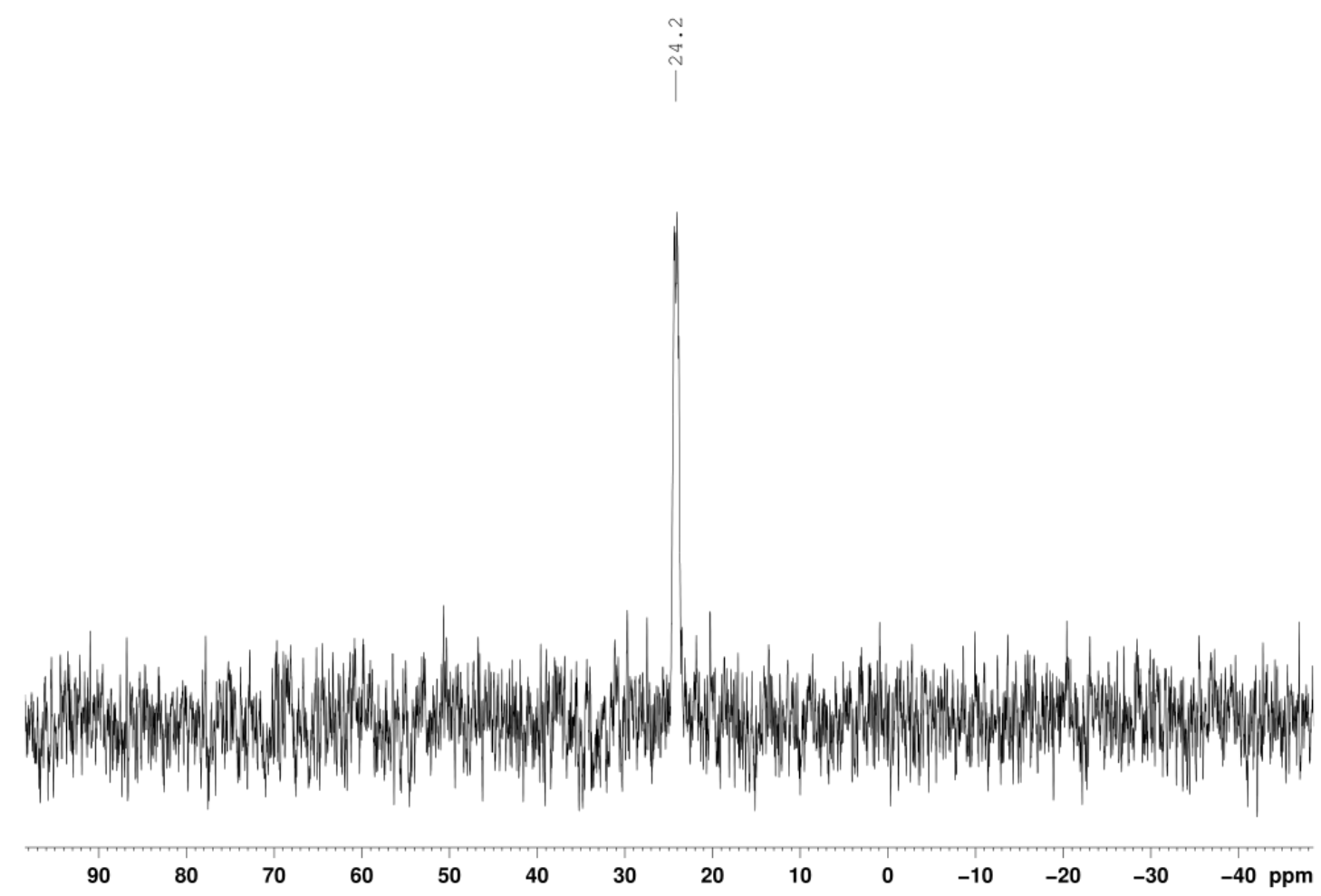

Figure 26. ${ }^{3 l} P\left\{{ }^{l} H\right\} N M R$ spectrum of complex $3 \mathrm{c}$ in $C_{6} D_{6}$.

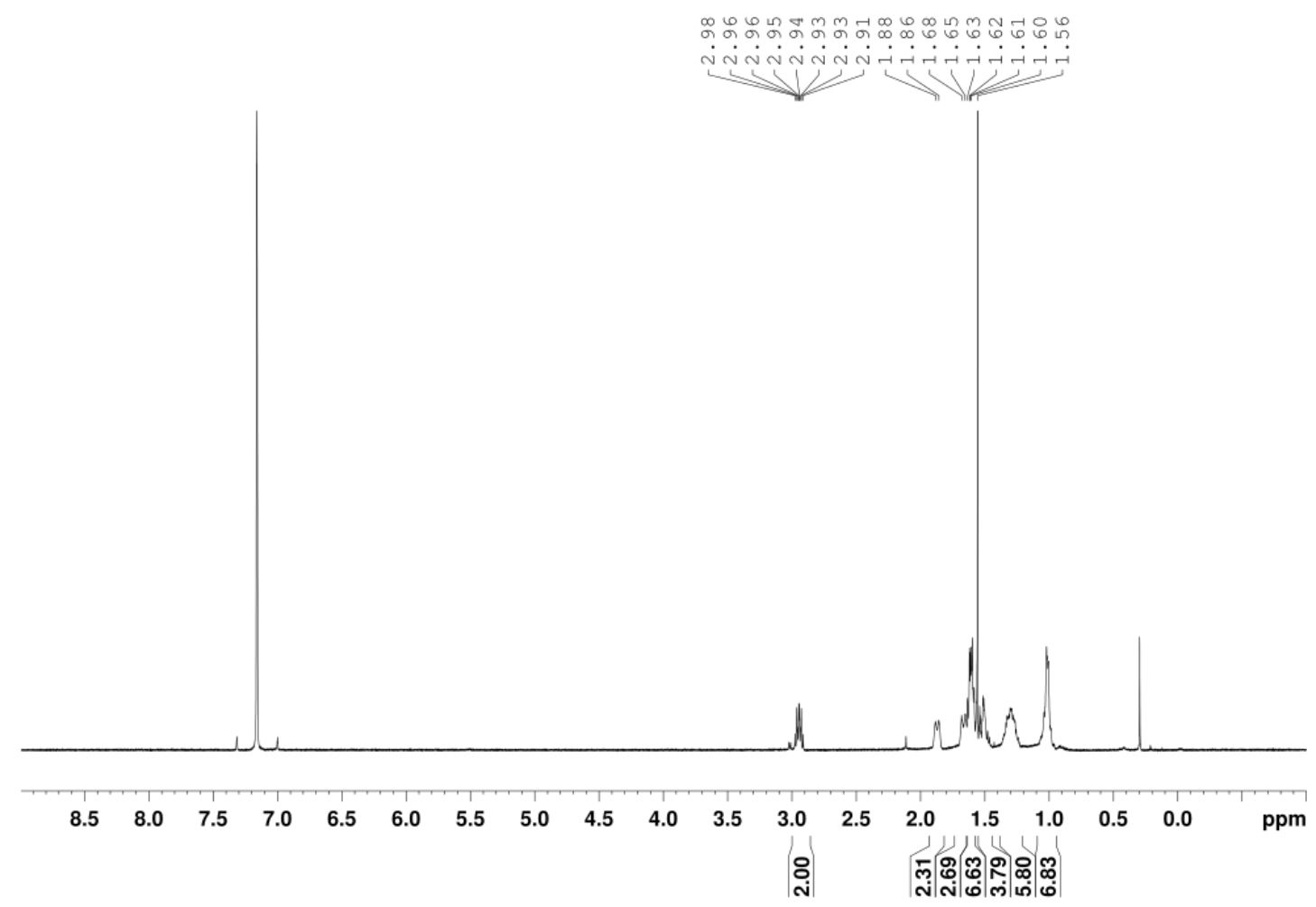

Figure 27. ${ }^{l} \mathrm{H}$ NMR spectrum of complex $3 \boldsymbol{c}$ in $C_{6} D_{6}$. 


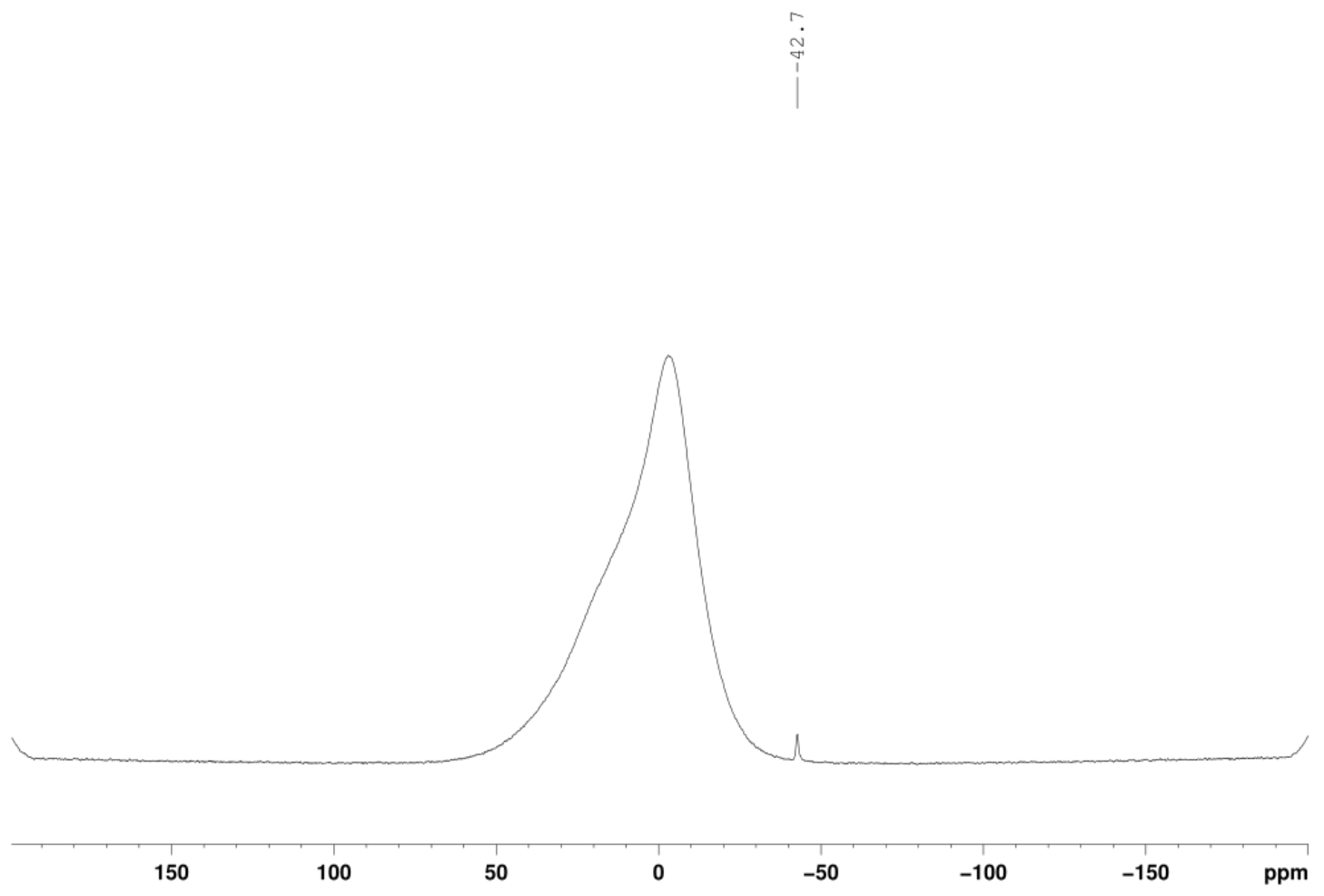

Figure 28. ${ }^{11} B\left[{ }^{1} H\right\}$ NMR spectrum of complex $3 \boldsymbol{c}$ in $C_{6} D_{6}$.

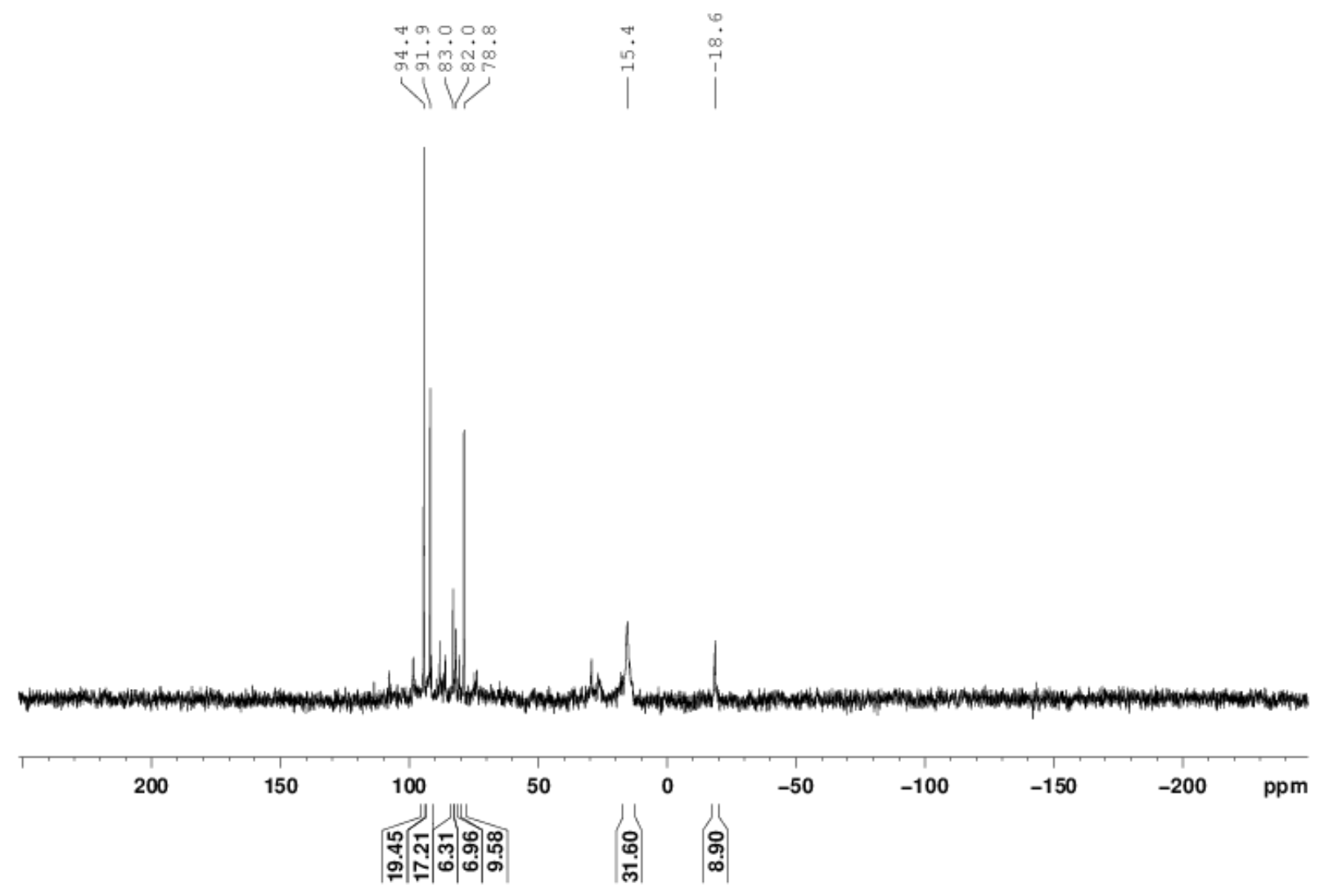

Figure 29. ${ }^{31} P\left\{{ }^{1} H\right\} N M R$ spectrum of multiple compounds with complex $4 d$ as main product in $C_{6} D_{6}$. 


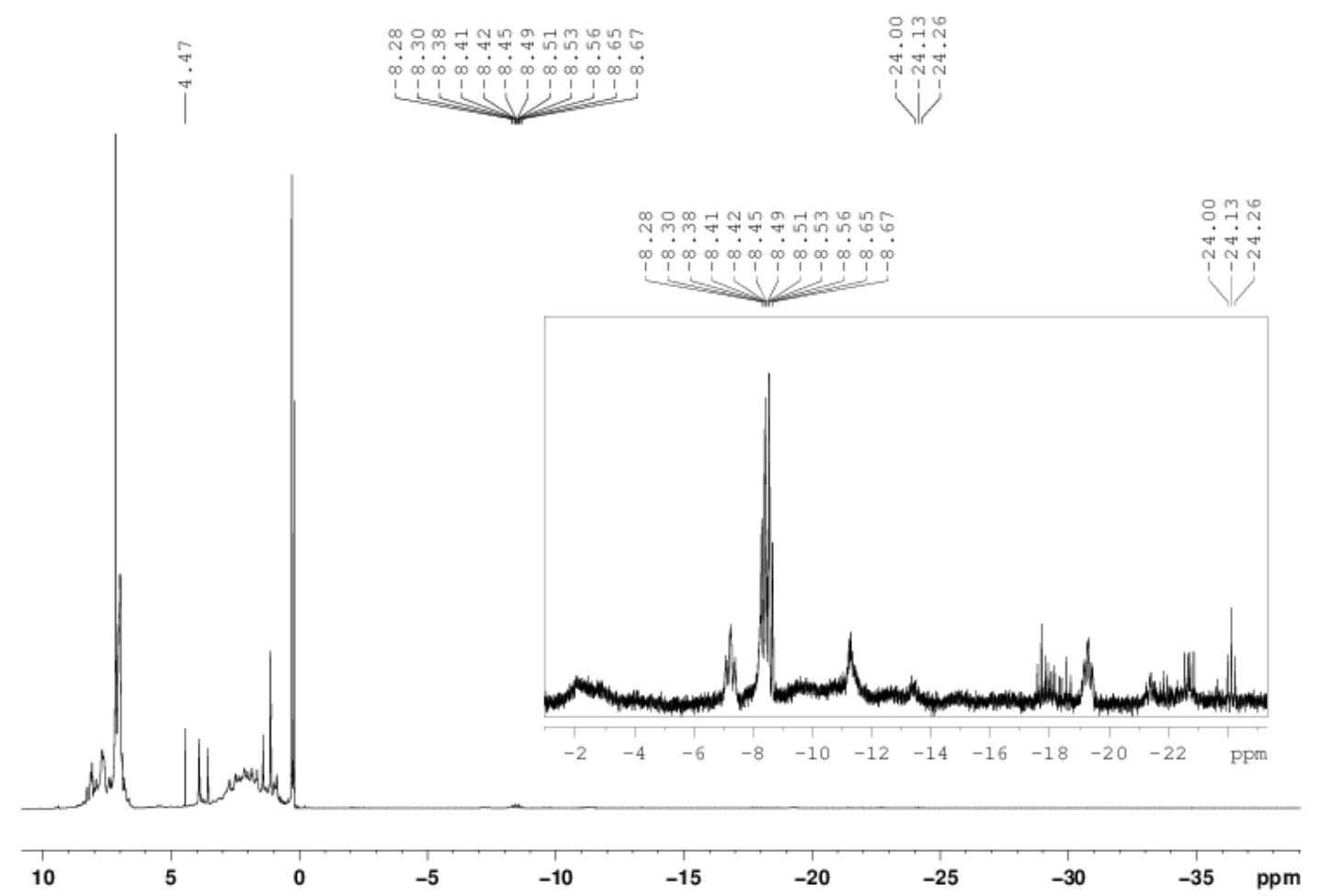

Figure 30. ${ }^{1} \mathrm{H} N \mathrm{NR}$ spectrum of multiple compounds with complex $4 \mathrm{~d}$ as main product in $C_{6} D_{6}$.

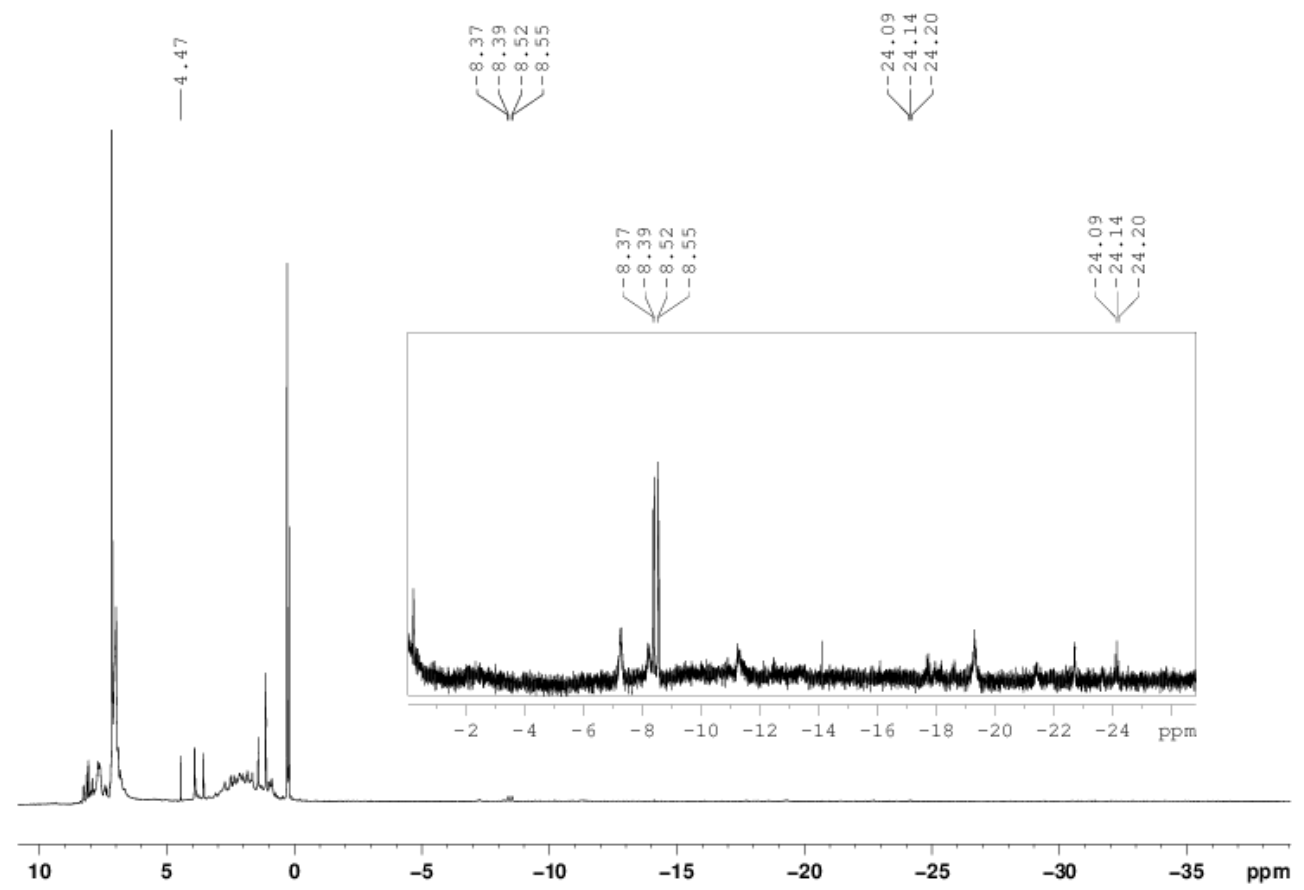

Figure 31. ${ }^{1} H_{\left\{{ }^{31} P\right\}} \mathrm{NMR}$ spectrum of multiple compounds with complex $4 \mathrm{~d}$ as main product in $\mathrm{C}_{6} \mathrm{D}_{6}$. 

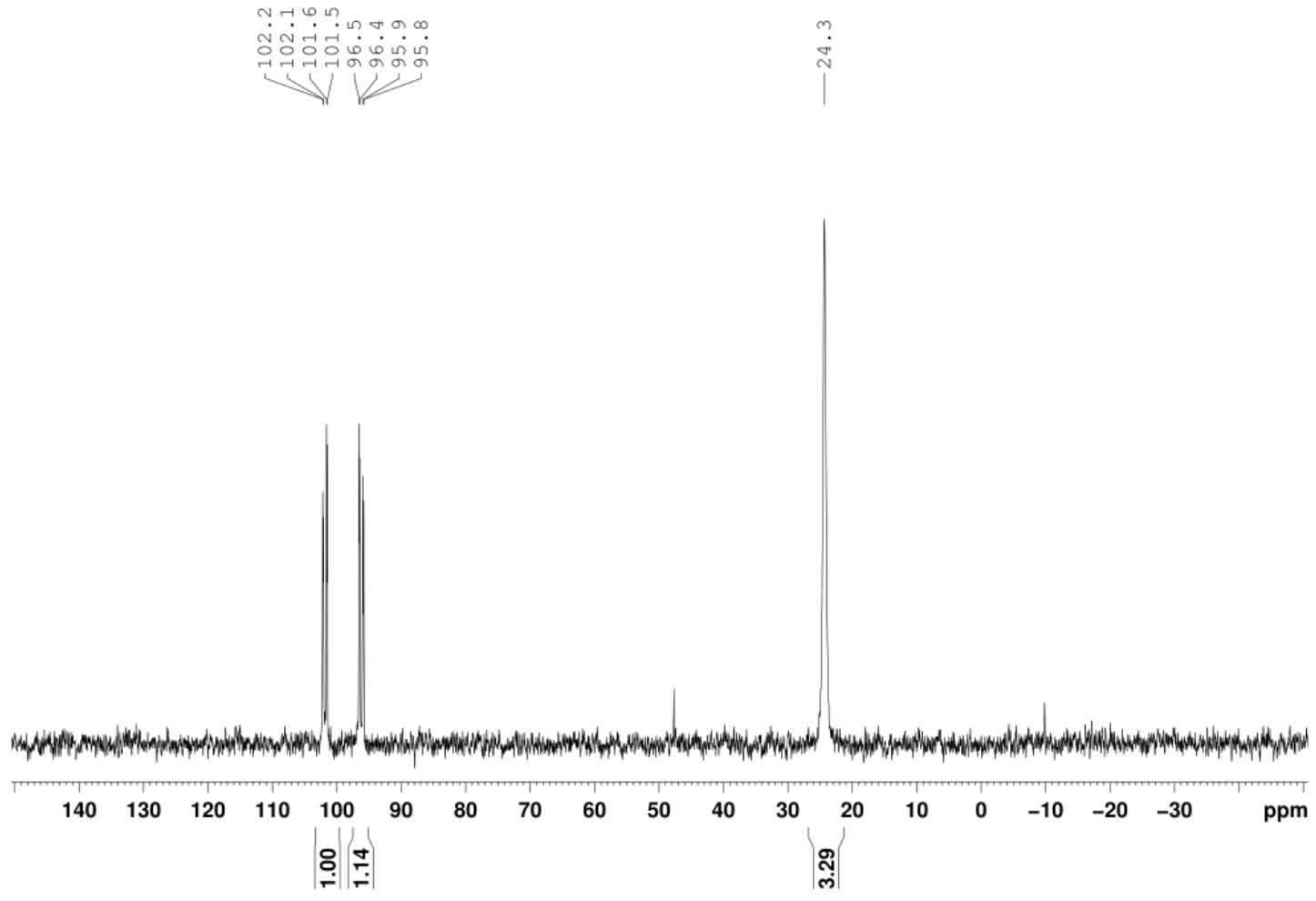

Figure 32. ${ }^{31} P\left\{{ }^{1} H\right\}$ NMR spectrum of complex $7 c$ in $C_{6} D_{6}$.

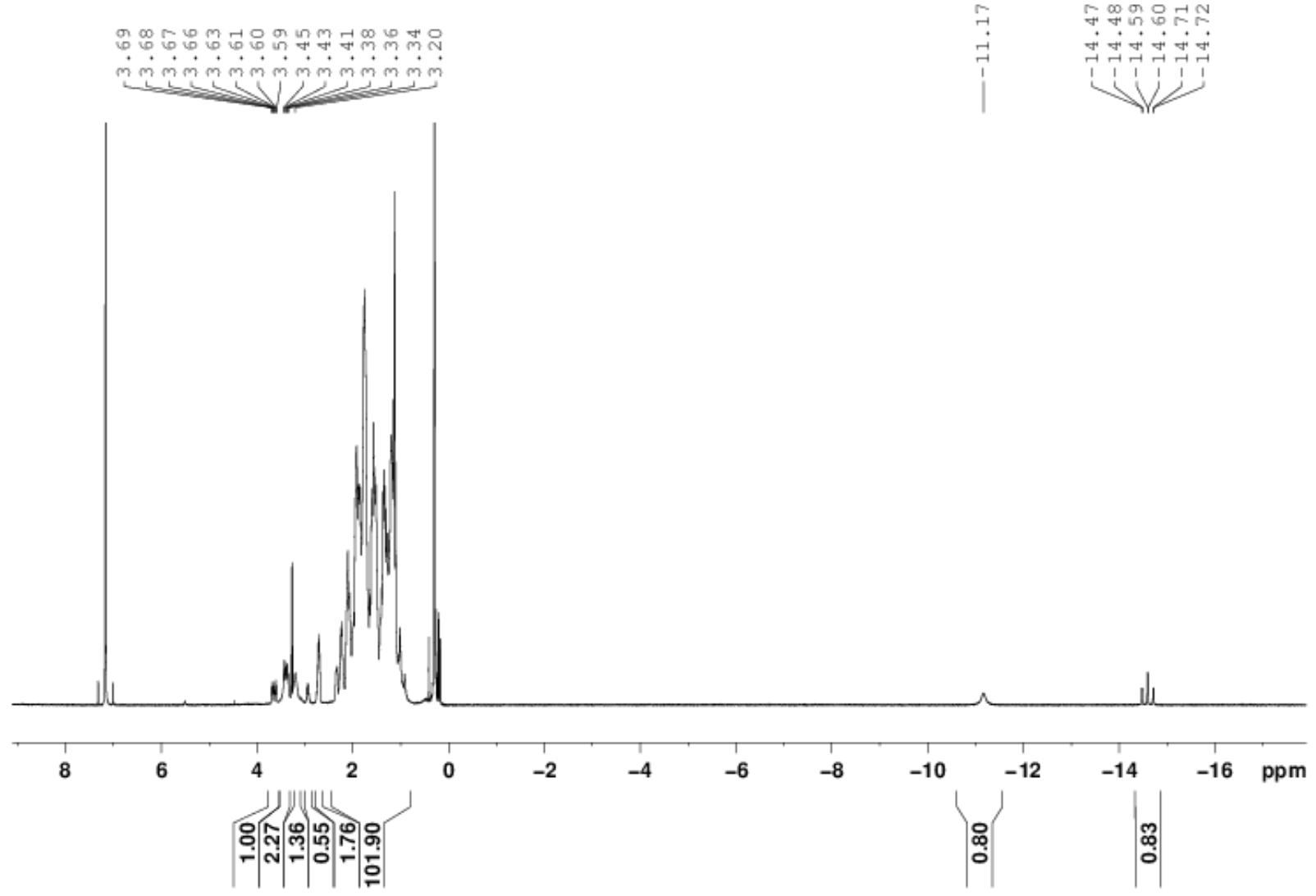

Figure 33. ${ }^{1} H\left\{{ }^{31} P\right\}$ NMR spectrum of complex $7 \boldsymbol{c}$ in $C_{6} D 6$. 

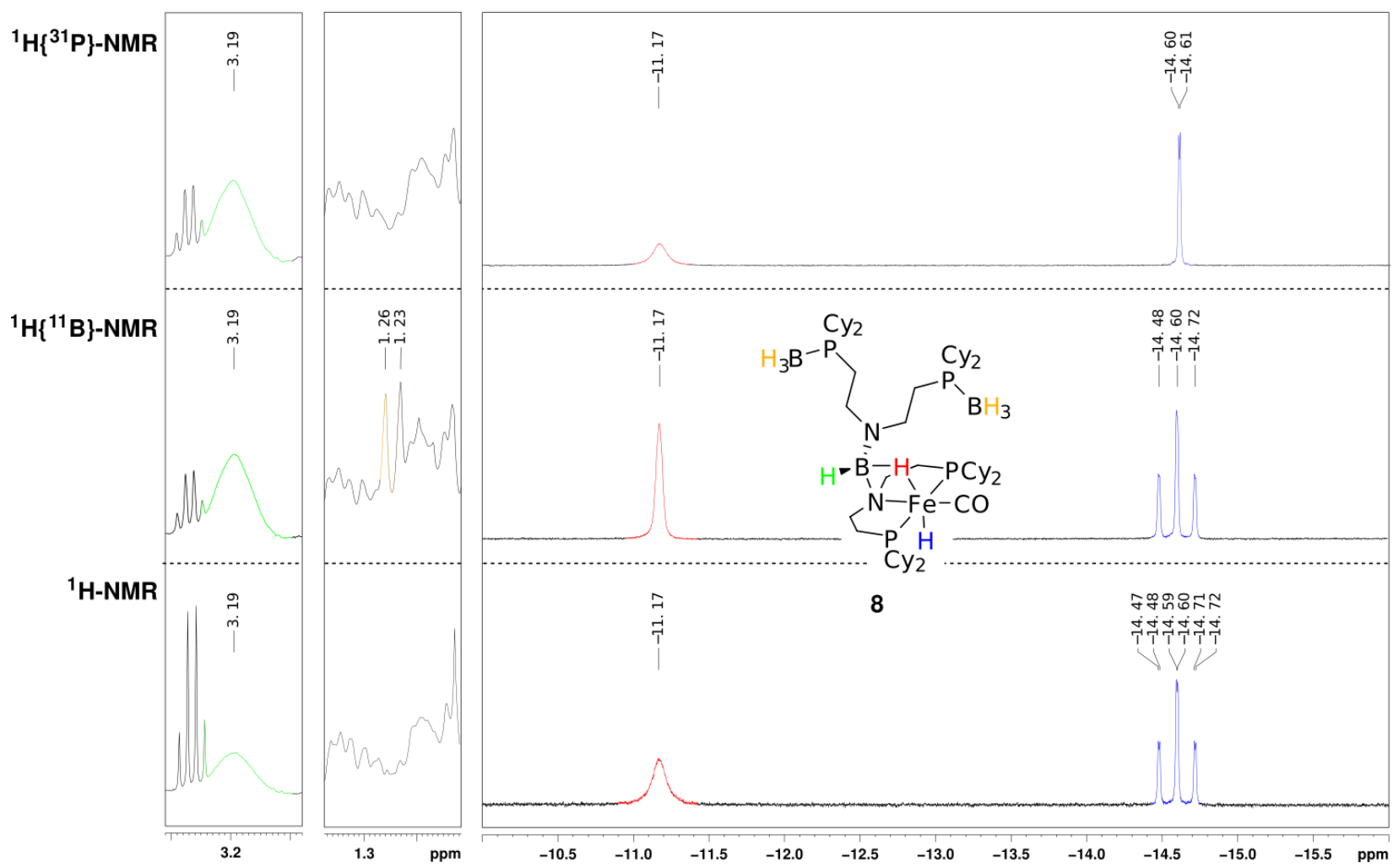

Figure 34. ${ }^{1} \mathrm{H}$ NMR spectrum of complex $7 \mathrm{c}$ in $C_{6} D_{6}$ with different decoupling.
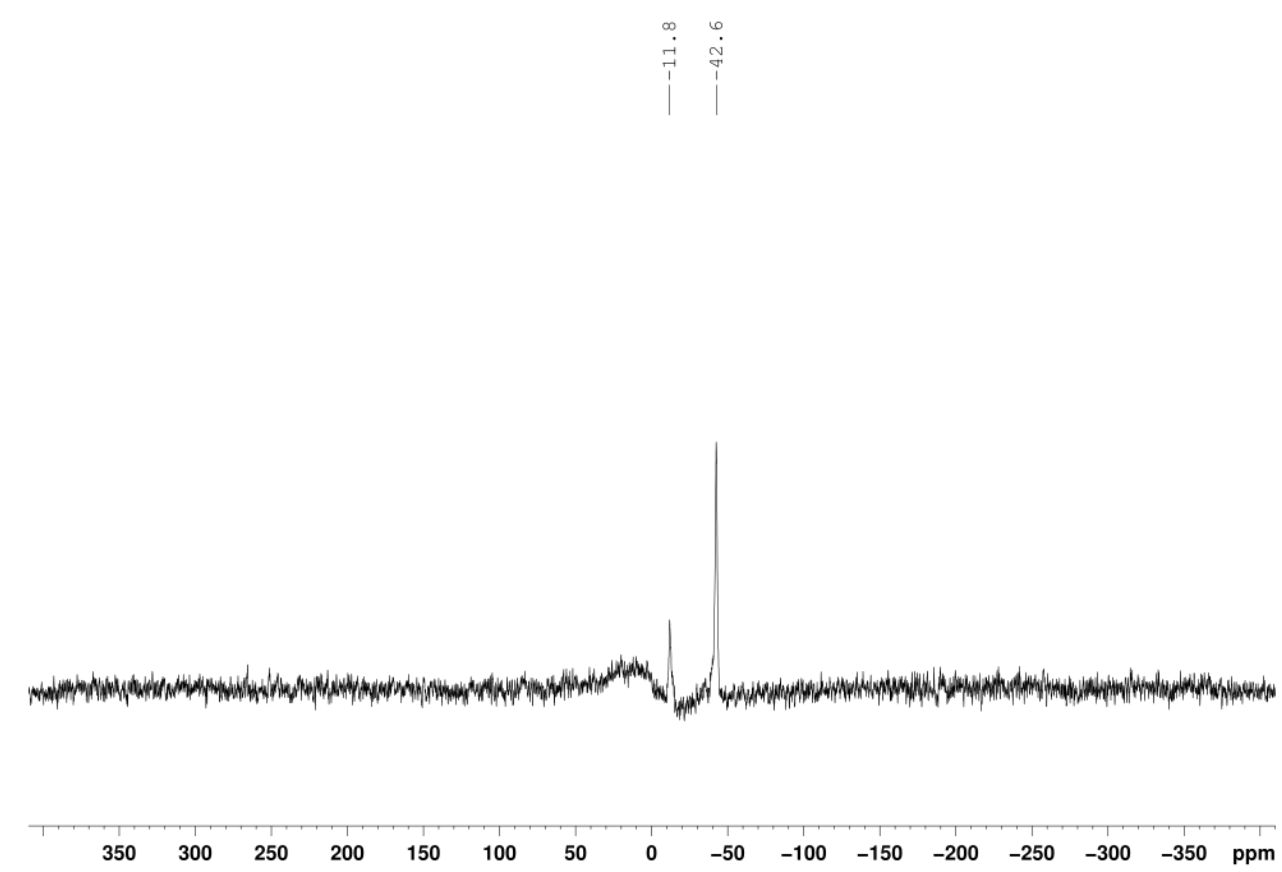

Figure 35. ${ }^{11} B\left\{{ }^{1} H\right\}$ NMR spectrum of complex $7 c$ in $C_{6} D_{6}$. 


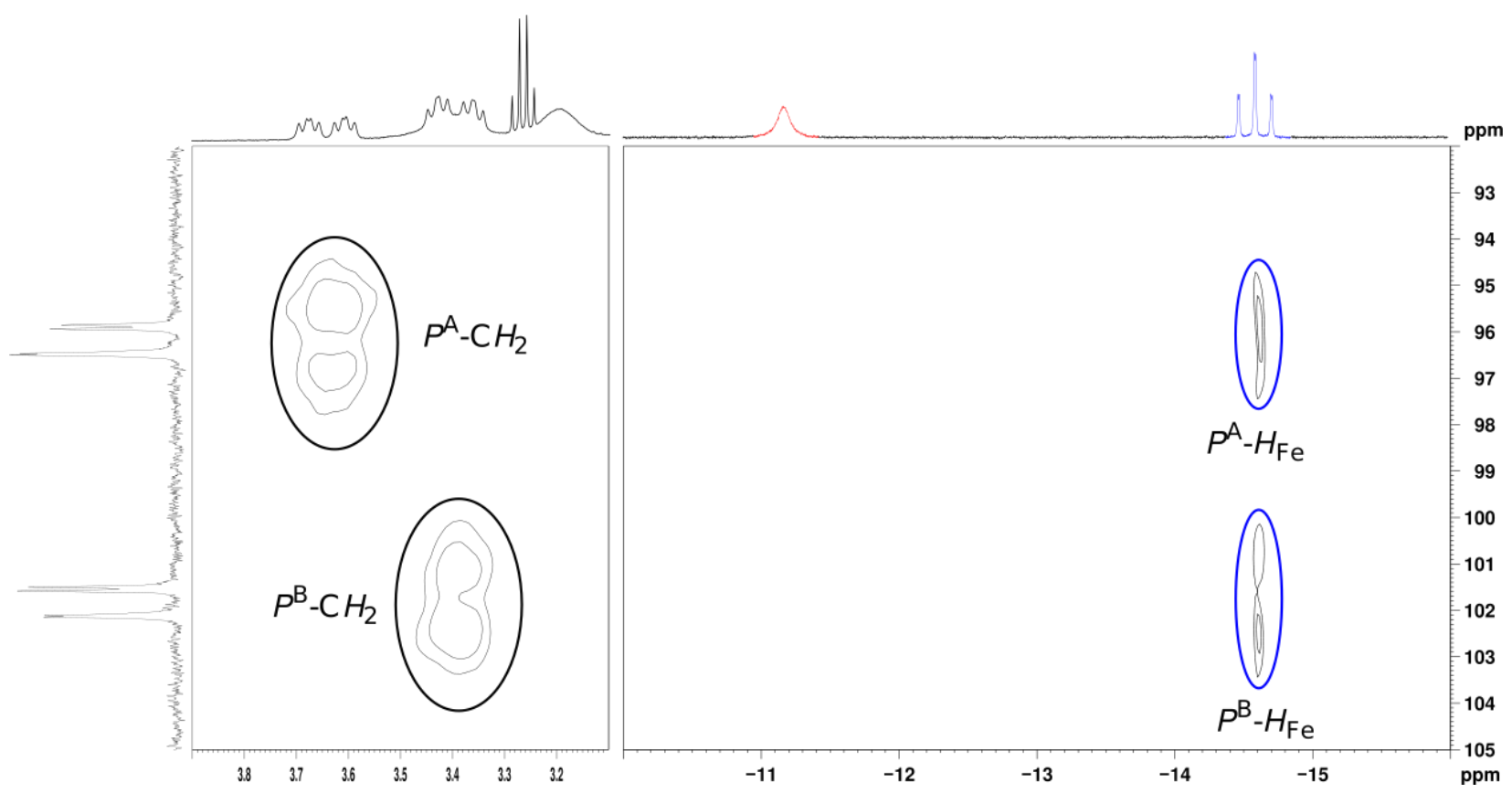

Figure 36. ${ }^{31} \mathrm{P}_{-}{ }^{l} \mathrm{H} H \mathrm{HMC}$ NMR spectrum of complex $7 \mathrm{c}$ in $\mathrm{C}_{6} \mathrm{D}_{6}$.

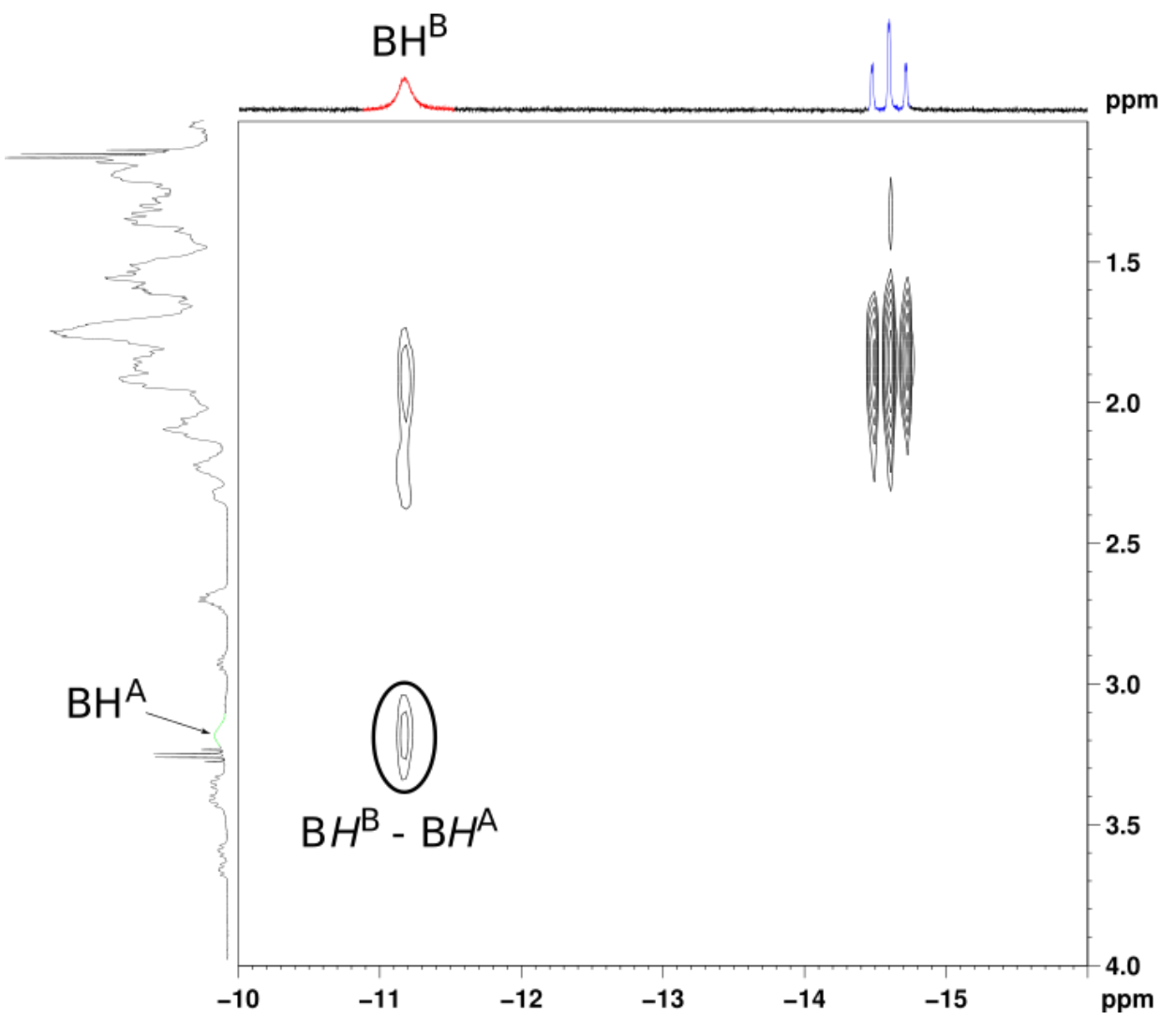

Figure 37. NOESY NMR spectrum of complex $7 \boldsymbol{c}$ in $C_{6} D_{6}$. 


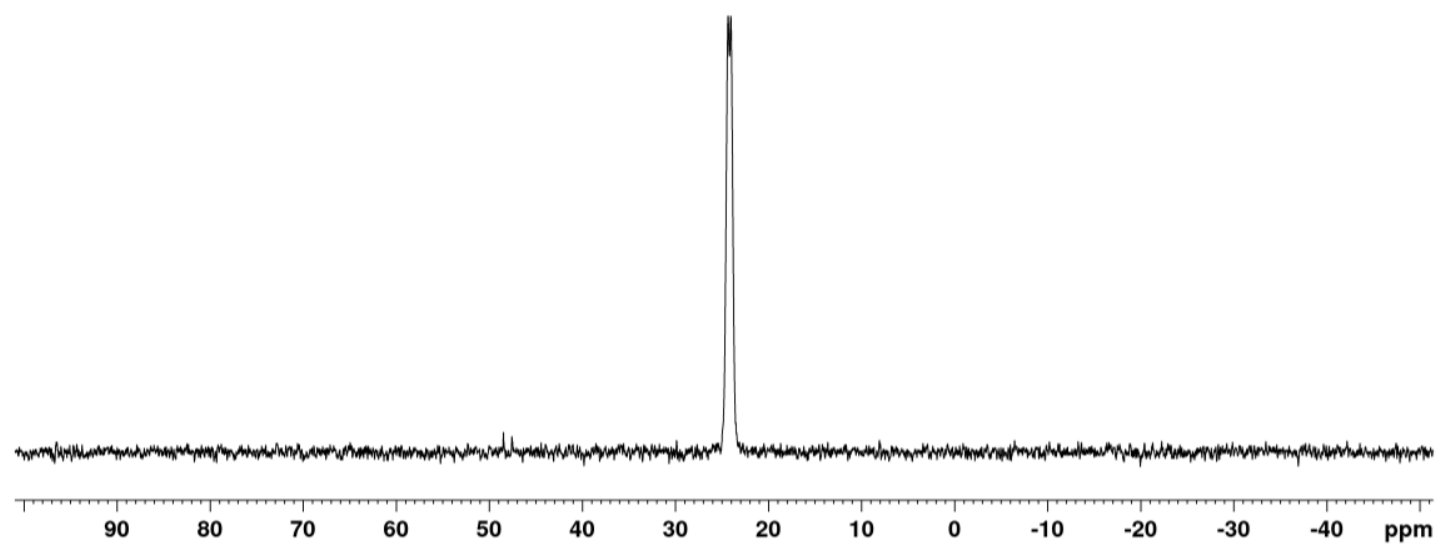

Figure 38. ${ }^{31} \mathrm{P}\left\{{ }^{1} \mathrm{H}\right\}$ NMR spectrum of complex $8 \mathrm{c}$ in $\mathrm{C}_{6} \mathrm{D}_{6}$.

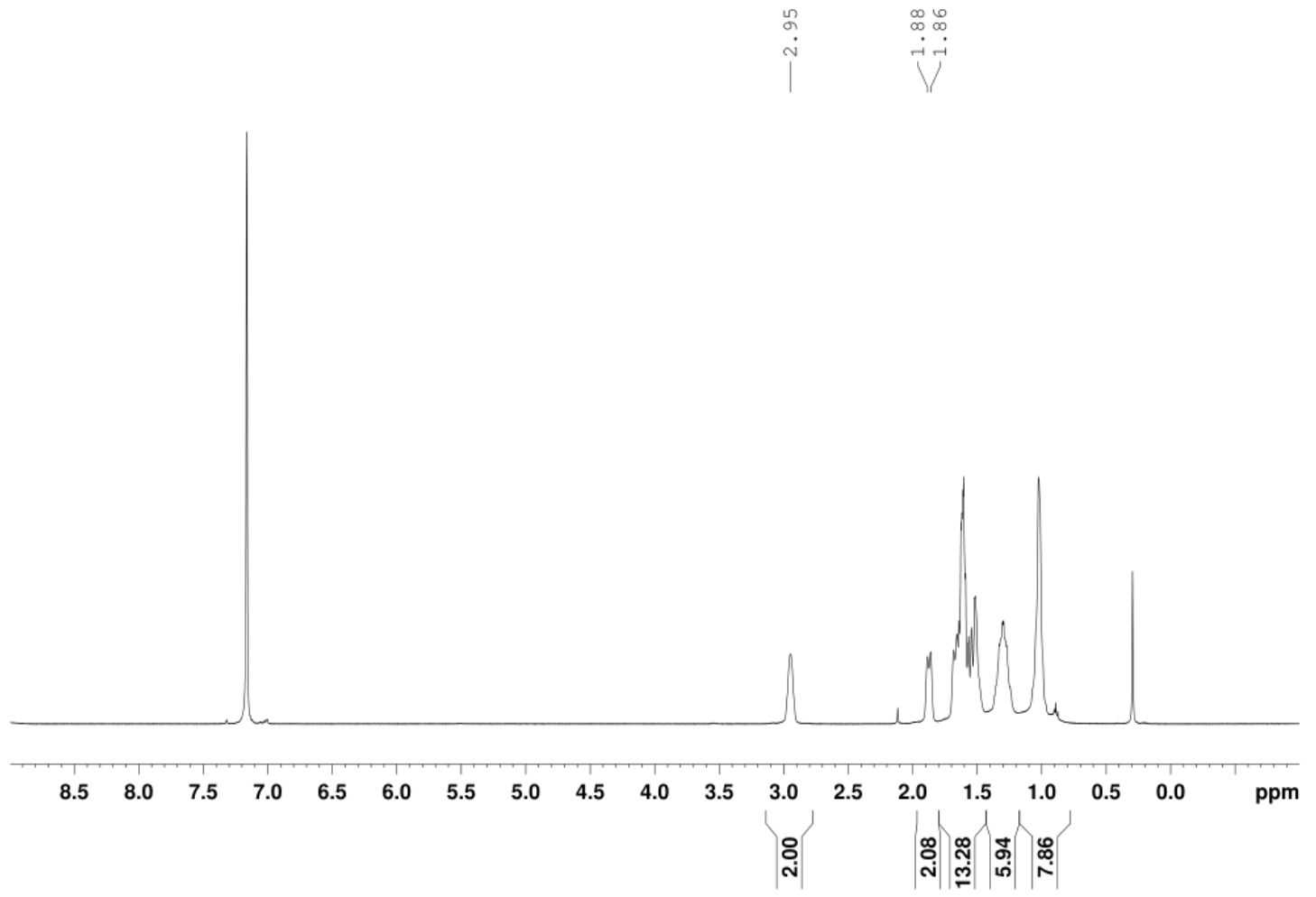

Figure 39. ${ }^{1} H$ NMR spectrum of complex $8 c$ in $C_{6} D_{6}$. 


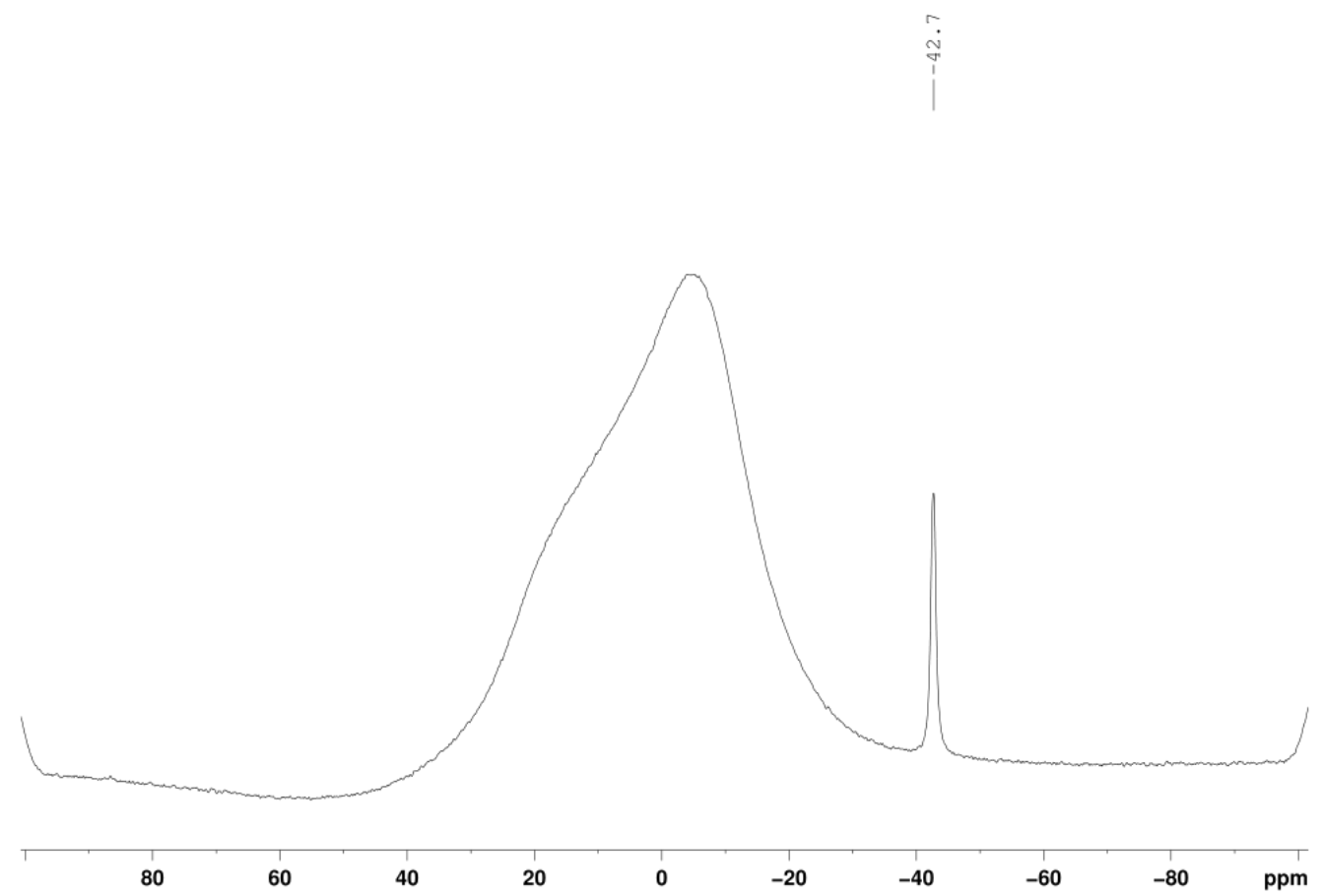

Figure 40. ${ }^{11} B\left\{{ }^{1} H\right\} N M R$ spectrum of complex $8 \mathrm{c}$ in $C_{6} D_{6}$.

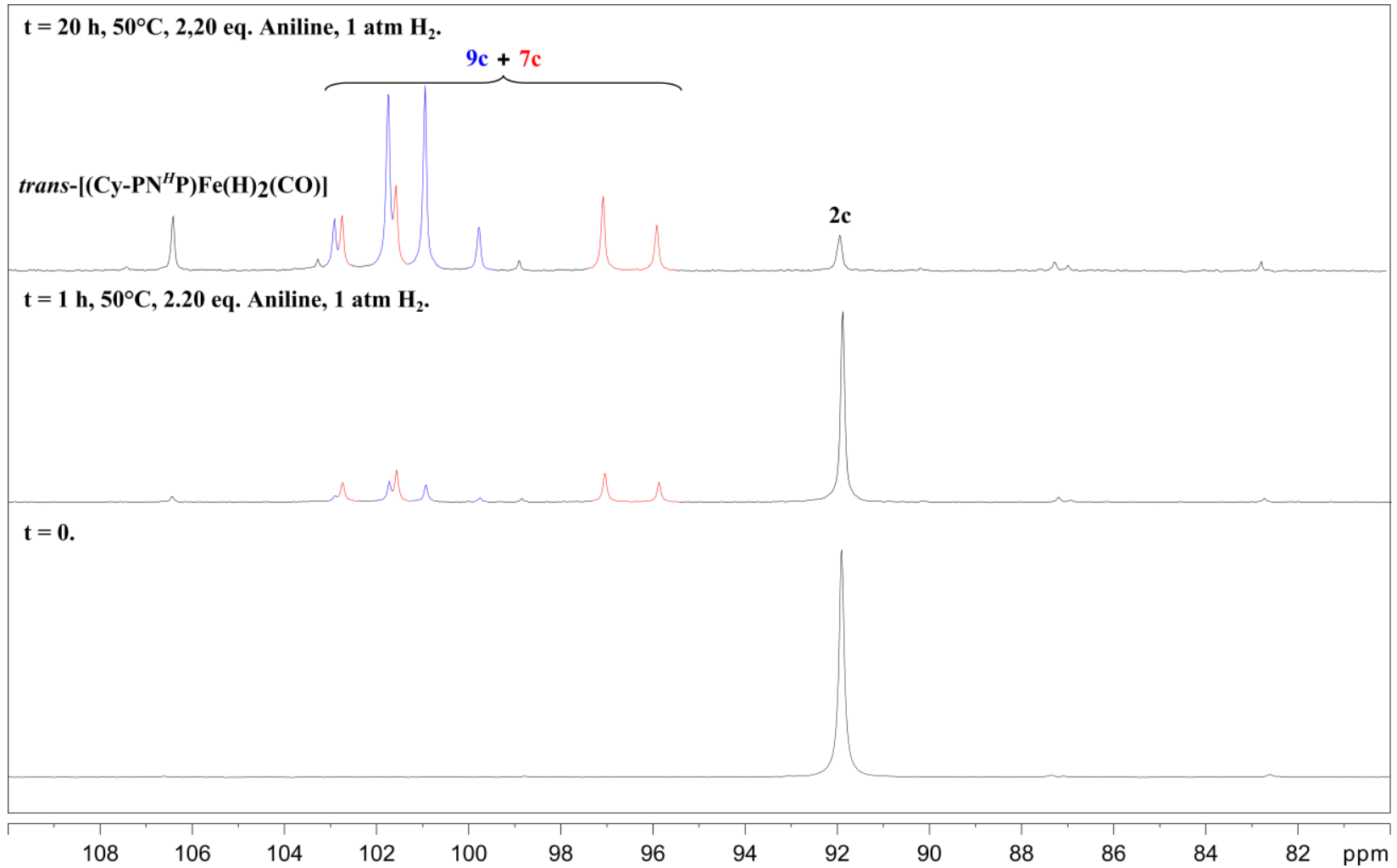

Figure 41. ${ }^{31} \mathrm{P}\left\{{ }^{1} \mathrm{H}\right\}$ NMR spectrum of conversion of $2 \mathrm{c}$ to $9 \mathrm{c}$ in $\mathrm{C}_{6} \mathrm{D}_{6}$. 


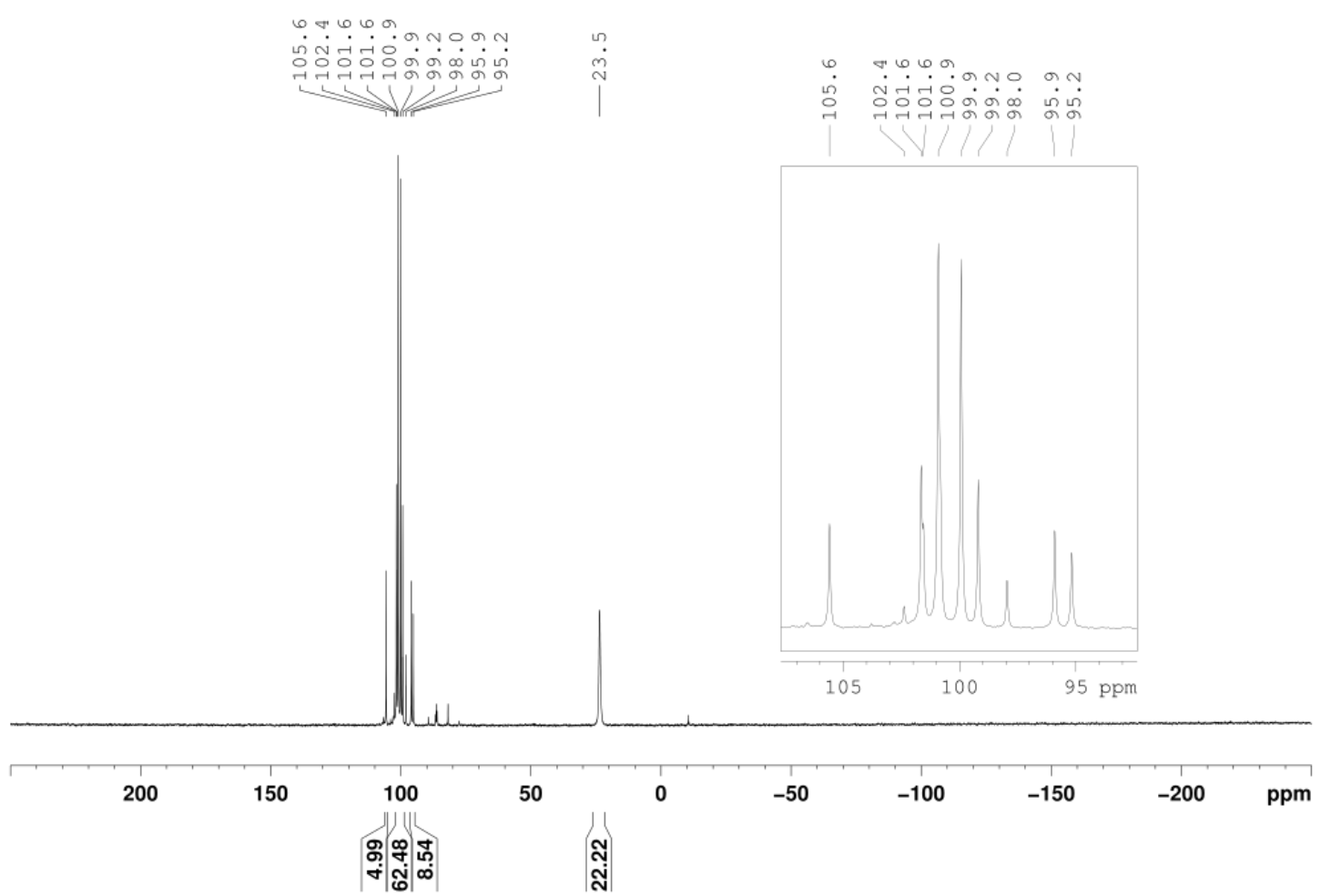

Figure 42. ${ }^{31} \mathrm{P}\left\{{ }^{1} \mathrm{H}\right\} \mathrm{NMR}$ spectrum of complex $9 \mathrm{c}$ in $\mathrm{C}_{6} \mathrm{D}_{6}$ containing $7 \mathrm{c}$ and trans-[(Cy-PN$\left.\left.{ }^{H} \mathrm{P}\right) \mathrm{Fe}(\mathrm{H})_{2}(\mathrm{CO})\right]$ as side product.

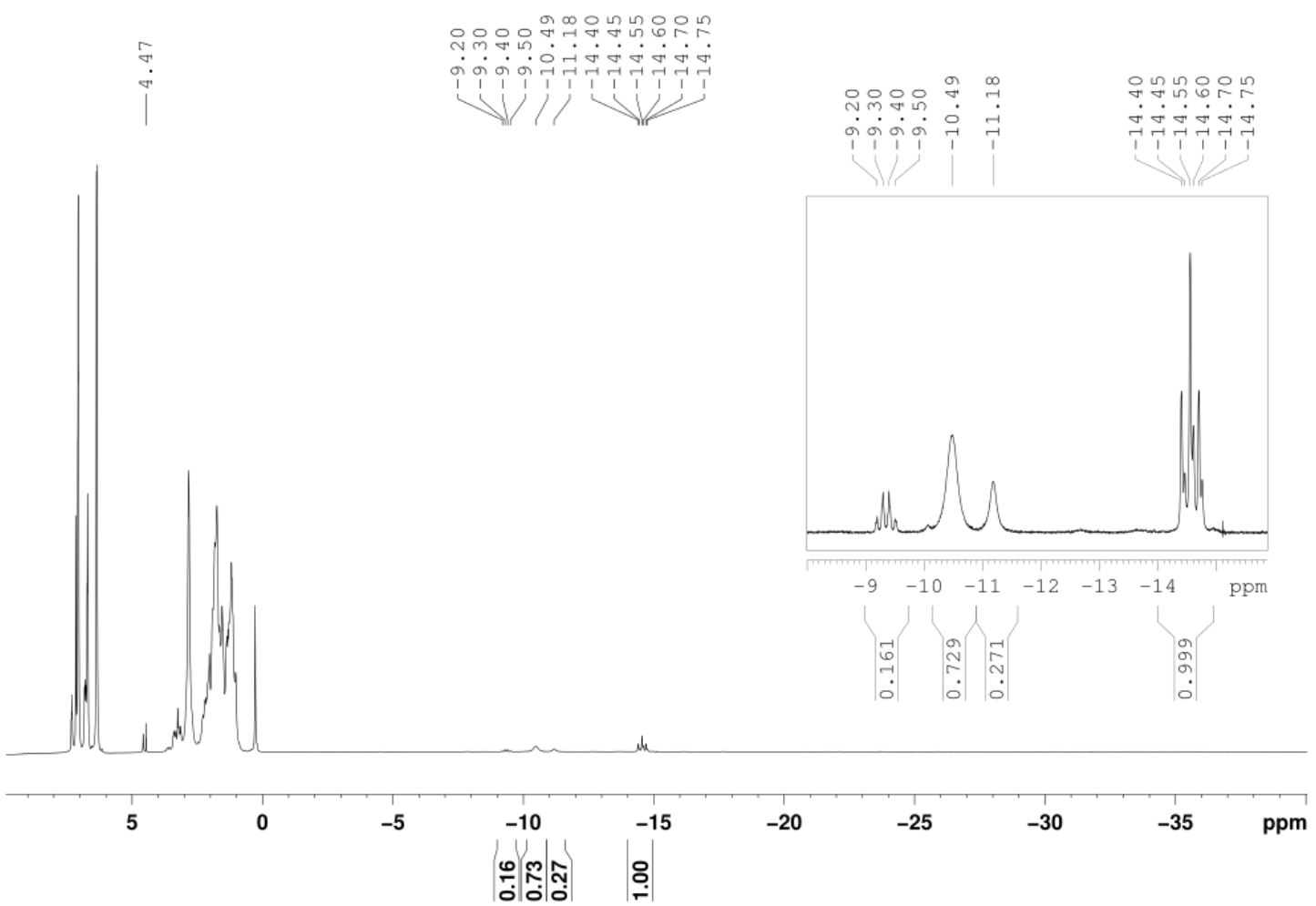

Figure 43. ${ }^{1} \mathrm{H}\left\{{ }^{31} \mathrm{P}\right\}$ NMR spectrum of complex $9 \mathrm{c}$ in $\mathrm{C}_{6} \mathrm{D}_{6}$ containing $7 \mathrm{c}$ and trans- $\left[\left(\mathrm{Cy}-\mathrm{PN} \mathrm{N}^{\mathrm{P}}\right) \mathrm{Fe}(\mathrm{H})_{2}(\mathrm{CO})\right]$ as side product. 


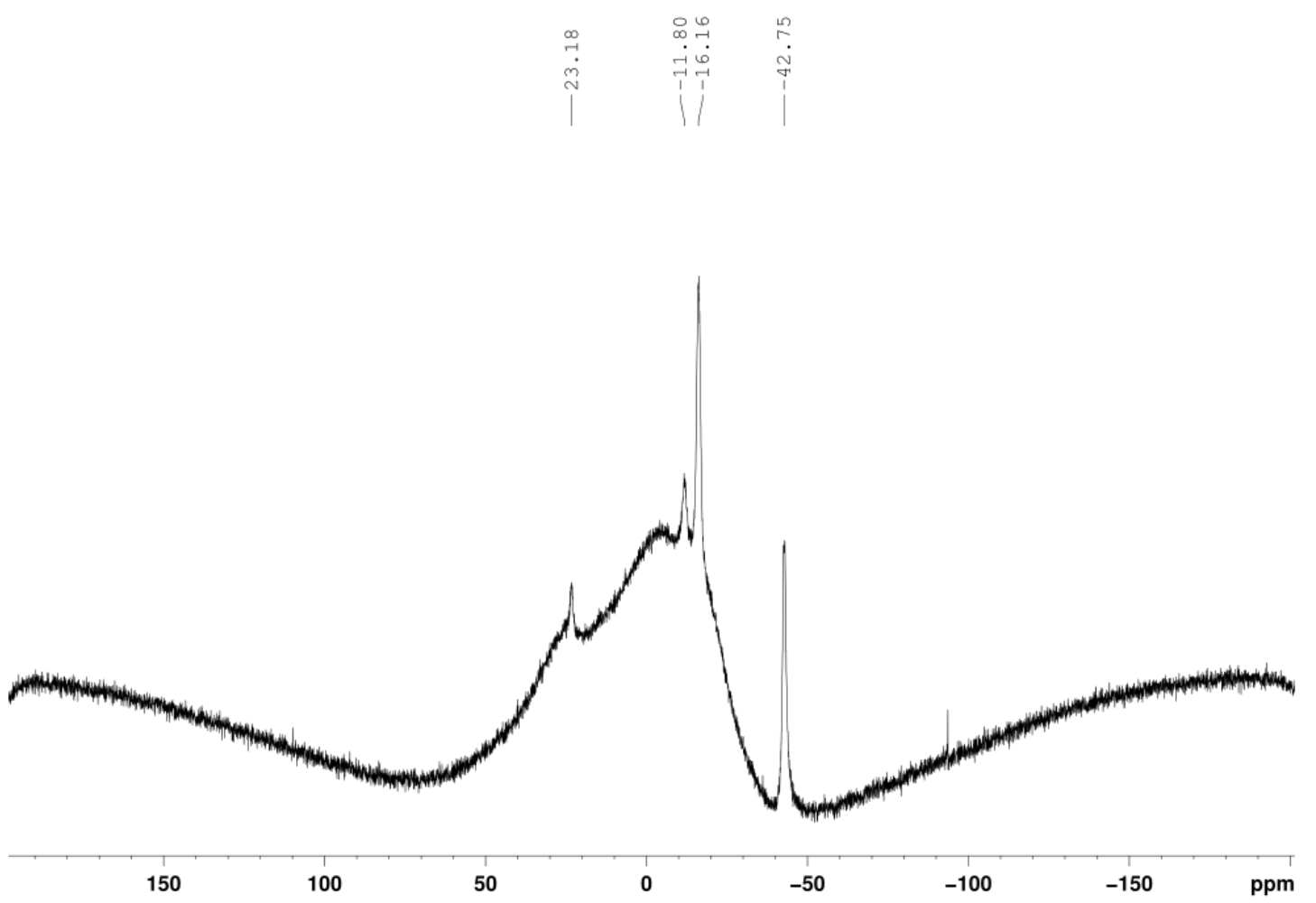

Figure 44. $\left.{ }^{11} \mathrm{~B}_{\{}{ }^{\mathrm{H}} \mathrm{H}\right\} \mathrm{NMR}$ spectrum of complex $9 \mathrm{c}$ in $\mathrm{C}_{6} \mathrm{D}_{6}$ containing $7 \mathrm{c}$ and trans-[(Cy-PN $\left.\left.\mathrm{H}\right) \mathrm{Fe}(\mathrm{H})_{2}(\mathrm{CO})\right]$ as side product.

(1) Chakraborty, S.; Dai, H.; Bhattacharya, P.; Fairweather, N. T.; Gibson, M. S.; Krause, J. A.; Guan, H. J. Am. Chem. Soc. 2014, 136, 7869.

(2) Koehne, I.; Schmeier, T. J.; Bielinski, E. A.; Pan, C. J.; Lagaditis, P. O.; Bernskoetter, W. H.; Takase, M. K.; Würtele, C.; Hazari, N.; Schneider, S. Inorg. Chem. 2014, 53, 2133. 